\title{
The C. elegans gonadal sheath Sh1 cells extend asymmetrically over a differentiating germ cell population in the proliferative zone
}

\author{
Xin Li ${ }^{1}$, Noor Singh ${ }^{1}$, Camille Miller ${ }^{1}$, India Washington ${ }^{1}$, Bintou Sosseh ${ }^{1}$, Kacy Lynn Gordon ${ }^{1, *}$ \\ 1Department of Biology, The University of North Carolina at Chapel Hill, Chapel Hill, NC, 27599, USA \\ *Correspondence: kacy.gordon@unc.edu \\ Department of Biology, CB \#3280, University of North Carolina at Chapel Hill, Chapel Hill, NC, 27599, \\ USA
}

\begin{abstract}
The $C$. elegans adult hermaphrodite germ line is surrounded by a thin tube formed by somatic sheath cells that support germ cells as they mature from the stem-like mitotic state through meiosis, gametogenesis and ovulation. Recently, we discovered that the distal-most Sh1 sheath cells associate with mitotic germ cells as they exit the niche. Here we report that these distal sheathassociated germ cells differentiate first in animals with temperature-sensitive mutations affecting germ cell state, and stem-like germ cells are maintained distal to the Sh1 boundary. We analyze several markers of the distal sheath, which is best visualized with endogenously tagged membrane proteins, as overexpressed fluorescent proteins fail to localize to distal membrane processes and can cause gonad morphology defects. However, such reagents with highly variable expression can be used to determine the relative positions of the two Sh1 cells, one of which often extends further distal than the other.
\end{abstract}

\section{Introduction}

The C. elegans hermaphrodite gonad is a fruitful system in which to study organogenesis, meiosis, and stem cell niche biology. Recent work from our group (Gordon et al., 2020), used two endogenously tagged alleles of genetically redundant innexin genes in $x-8$ and inx- 9 to visualize the somatic gonadal sheath of the $C$. elegans hermaphrodite. We discovered that the distal most pair of sheath cells, called Sh1, lies immediately adjacent to the distal tip cell (DTC), which is the stem cell niche of the germ line stem cells. Previously (based on electron microscopy and on cytoplasmic GFP overexpression from transgenes active in the sheath (lim-7p::GFP) (Hall et al., 1999) or its progenitor cells (lag-2p:::GFP) (Killian and Hubbard, 2005)), Sh1 cells were thought to associate only with germ cells well into the meiotic cell cycle, so our finding required a reimagining of the anatomy of the distal gonad.

Here, we confirm that the Sh1 cells fall at the boundary of a population of germ cells in a stem-like state, report other markers that label the Sh1 cells, and verify that these markers can be used to assess gonad anatomy without unduly impacting the gonad itself. We also discuss reagents that are not suitable markers of Sh1 cells, including an overexpressed, functional cell death receptor that is used to mark Sh1 in a recent study (Tolkin et al., 2021). Finally, we consider best practices for using endogenously tagged proteins for cell and developmental studies.

\section{Results}

Distal Sh1 associates with the population of germ cells that differentiate first when progression through mitosis is halted or Notch signaling is lost

The DTC expresses the Notch ligand LAG-2, which is necessary to maintain the germ line stem cell pool (Henderson et al., 1994). Recent work has shown that the active transcription of Notch targets sygl-1 and Ist-1 (Lee et al., 2019) and the accumulation of their proteins (Shin et al., 2017) is restricted to the distal-most germ cells, describing a population of stem-like germ cells $\sim 6-8$ germ cell diameters $(\sim 30-40 \mu \mathrm{m})$ from the distal end of the gonad. A similar spatial arrangement was found in earlier work that used an emb-30 temperature-sensitive allele to arrest germ cell division, thus halting the distal-to-proximal movement of germ cells and allowing cells to differentiate outside of the niche and remain undifferentiated in the niche (Cinquin et al., 2010). Similar results were obtained using g/p-1 temperature sensitive alleles to stop Notch signal transduction and observe where and when germ cells acquire markers of differentiation (Cinquin et al., 2010), though germ cell cycle also influences the timing of differentiation (Fox and Schedl, 2015). Our recent work (Gordon et al., 2020) 
reported that the position of Sh1 coincides with sygl-1 promoter's expression boundary on one side and the accumulation of the meiotic entry protein GLD-1 on the other, consistent with the hypothesis that the distal edge of Sh1 falls at the boundary of that stem-like cell population, $\sim 30 \mu \mathrm{m}$ from the distal end of the gonad.

We undertook a functional test of this hypothesis. We predicted that the distal edge of Sh1 would extend over the germ cell population just outside the niche, observed as the transition in germ cell nuclear morphologies characteristic of emb-30(tn377) mutants at the restrictive temperature that arrest at the metaphase/anaphase transition, or the pachytene crescents of meiosis I in glp-1(bn18) mutants at the restrictive temperature. Furthermore, we predicted that the position of the Sh1 cell would be unaffected by these alleles, reasoning that the Sh1 cells sit atop a more-differentiated set of proliferative zone cells, and these germ cells simply differentiate in place under Sh1 when the mutants are placed at the restrictive temperature.

As predicted, we found that the emb-30 and glp-1 temperature sensitive loss of function alleles at the restrictive temperature reveal that the Sh1 cells directly abut the stem-like germ cell population, but the alleles do not affect the position of Sh1 (Figure 1). Results from these temperature sensitive mutants confirm what the markers of germ cell fate revealed in Gordon et al. (2020), which is that the Sh1 cell associates with germ cells in the proliferative zone that have left the stem cell niche and are on the path to differentiation, while the stem-like germ cells lie immediately distal to the Sh1 cell at its interface with the DTC.

\section{Different endogenously tagged membrane proteins reveal a distal position of Sh1}

These experiments made use of the endogenously N-terminal tagged inx-8(qy78[mKate::inx-8]) and inx-9(qy79[GFP::inx-9]) alleles (Figure 2A and B) generated by (Gordon et al., 2020). Both tagged alleles are highly specific for the somatic gonad throughout development; in the adult, their expression differentiates, with INX-8 signal diminishing from the DTC and INX-9 signal persisting (see white DTC outline in Figure 1D). We have since been looking for additional endogenous fluorescentprotein-tagged alleles that show expression in the gonadal sheath cells and localize in or near the cell membrane. One of these, ina-1 (qy23[ina-1::mNeonGreen]) (Figure 2C) was briefly reported in (Gordon et al., 2020). We found another that marks the sheath, cam-1(cp243[cam$1:: m$ NeonGreen])(Heppert et al., 2018) (Figure 2D). Widely expressed proteins found in the gonadal sheath and in the underlying germ cells or overlying body wall muscle cells (e.g. arx-2, cdc-42, sdn-1) are difficult to resolve at the gonad surface. For both tagged innexins, as well as ina-1::mNG and cam-1::mNG, we find that the Sh1 cell has a distal boundary that either displays a measurable interface with the DTC or is so located as to be consistent with such a boundary (where the DTC is not marked by the endogenous protein). The position of this boundary ( 25-40 $\mu \mathrm{m}$, or 5-8 germ cell diameters) coincides with the domain in which germ cells leave the stem cell niche (Lee et al., 2019) (Figure 2E). We have not yet found a counterexample of an endogenously tagged, membraneassociated protein in Sh1 that demarcates an apparent Sh1 cell boundary at a great distance from the distal end of the gonad in young adults.

\section{Overexpressed transgenic markers vary in distal position and expression levels}

Three integrated array transgene markers that drive overexpression of fluorescent proteins in the sheath were also analyzed. The first is a lim-7 promoter-driven cytoplasmic GFP that was used to label the Sh1 cell in a foundational study of the $C$. elegans hermaphrodite gonad, tn/s6[lim-7::GFP] (Hall et al., 1999) (Figure 2F). The second is a lim-7 promoter-driven functional cell death receptor tagged with GFP, bcls39[lim-7p::ced-1::GFP] (Zhou et al., 2001), which is the basis of a recent study that reports a more proximal boundary of Sh1 (Figure 2G, strain DG5020 (Tolkin et al., 2021)). The third is a lim-7 promoter-driven membrane-localized GFP made by us to mark the sheath cell membrane without tagging an endogenous protein, rlmIs5[lim-7p::GFP::CAAX] (Figure $2 \mathrm{H}$ ). The range of the distal edge of GFP localization for all three strains overlaps with what we observed for the four endogenously tagged proteins, but are far more variable, as overexpressed transgenes are known to be (Evans, 2006) (Figure 2E-H, and Figure 2 Supplement 1).

To untangle this variance, we examined individual worms for evidence of a DTC-Sh1 interface. About 
half of the scoreable lim-7p::ced-1::GFP gonads (strain DG5020) show a DTC-Sh1 interface, and half show a bare region (Figure $3 \mathrm{~A}$ ). We further broke down this dataset by fluorescence intensity of distal CED-1::GFP signal. Strikingly, among animals under a threshold of expression intensity of $\sim 400 \mathrm{~A}$.U. (less than $1 / 3$ as bright as the brightest GFP samples), the incidence of a DTC-Sh1 interface was $100 \%$ (10/10, as opposed to $15 / 30$ for the whole dataset). On the other extreme, gonads with stronger CED-1::GFP signal were more likely to have a farther proximal boundary of CED-1::GFP localization. In samples for which CED-1::GFP signal terminates at a great distance from the distal end of the gonad, there are two possible explanations. Either in those animals, the Sh1 position is farther distal than in animals with other markers, or else CED-1::GFP fails to localize to the edge of the Sh1 cell pair.

\section{Expression differences between Sh1 cells in a pair can conceal distal extent of the sheath}

We observed a pattern in a subset of gonads where the two Sh1 cells of a pair had dramatically different levels of CED-1::GFP signal, and these cells had different terminal positions on the distalproximal axis (Figure 3B and 3B'). Exposure time and excitation laser power during image acquisition and subsequent scaling of the resulting image determine whether or not the signal in the lowly expressing cell is readily apparent (Figure 3B vs 3B'). In some cases, the brightness of the other Sh1 cell and the nearby proximal gonad makes the dimmer Sh1 cell nearly impossible to detect. Variable expression levels and even complete silencing of $C$. elegans transgenes are well-known phenomena (Evans, 2006). It was not known, however, that the two Sh1 cells of a pair could assume such different configurations over the distal germline (Figure $3 \mathrm{C}$, and see Figure $2 \mathrm{H}$ for the same pattern in the lim-7p::GFP::CAAX transgenic strain).

The Sh1 positions become even more clear when lim-7p:::ced-1::GFP is coexpressed with the mKatetagged innexin inx-8(qy78) in strain DG5131 (Figure 3D and 3E). These markers colocalize in a substantial fraction of animals, as has been reported recently ((Tolkin et al., 2021), see Figure 2 Supplement 2 therein). In the animals that have a discrepancy between GFP and mKate localization in Sh1, the difference in expression reveals an unexpected cell boundary between the two Sh1 cells. We imaged 19 gonads from the coexpressing strain DG5131 through their full thickness. Of those, $4 / 19$ had severe gonad morphology defects (see next section). Of the 15 morphologically normal gonads, 6/15 had discrepancies in CED-1::GFP and mKate::INX-8 signal. In 3/6 such cases, one Sh1 cell makes up the entire DTC-Sh1 interface, with the other terminating at a greater distance from the distal end. Fluorescence signal from mKate::INX-8 alone does not allow these cell borders to be detected because that marker is more consistently expressed across the Sh1 cells (Figure 3F).

The variability of the lim-7p::ced-1::GFP transgene allowed us to perform something like a mosaic analysis when the two Sh1 cells have very different expression levels but the dimmer cell is still visible ( $\mathrm{N}=31 / 53$ morphologically normal DG5020 gonads imaged to full depth, Figure 3 Supplement 1A-D). Where the borders of the two Sh1 cells can be distinguished, one cell extends at least $20 \mu \mathrm{m}$ farther distal than the other in 23/31 cases; five additional gonads have expression in only one Sh1 cell that terminates at a great distance $(>70 \mu \mathrm{m})$ from the distal end. The edges of dimly expressing Sh1 cells can be difficult to resolve. A similar phenomenon was observed when the cytoplasmic GFP of tnls6[lim-7p::GFP] was coexpressed with qy78[mKate::inx-8] ((Gordon et al., 2020) Figure 1 Supplement 1 therein). Of note, the N-terminal mKate::INX-8 and GFP::INX-9 tags are most likely extracellular based on the innexin-6 channel structure determined by cryo-EM (Oshima et al., 2016), so there is reason to suspect their localization at the cell membrane will be regulated differently than that of intracellular GFPs.

Additionally, we noticed that in DG5131 gonads where the two Sh1 cells have very different CED$1::$ GFP expression levels, sometimes mKate::INX-8 is missing from the membrane in Sh1 cells with strong CED-1::GFP signal (Figure 3 Supplement $1 E$ and $1 F$ ). Subtracting background, we find that there is a $50 \%$ reduction in tagged INX-8 in such membrane regions. Since mKate::INX-8 is a genomically encoded, functional protein, such disruption likely impacts endogenous protein function. This observation hints at a synthetic interaction between the two fluorescent sheath membrane proteins. 


\section{Overexpression of CED-1::GFP transgene is correlated with gonad abnormalities}

We therefore asked whether there was further evidence of a synthetic interaction between lim$7 p:: c e d-1:: G F P$ and inx-8(qy78). First, we found evidence that suggests that lim-7p:::ced-1::GFP is damaging to the animals with or without $q y 78$. In the strain that expresses lim-7p::ced-1::GFP and not qy78 (strain DG5020), roughly $20 \%$ of the animals had profound gonad migration defects in one gonad arm (Figure 4A, 4C). This was the case in two parallel lineages we revived, both before and after several generations of passaging without starvation or crowding on the plates. We also observe such defects in the DG5131 strain that combines qy78[mKate::inx-8] with the lim-7p::ced-1::GFP transgene (Figure $4 \mathrm{~B}, 4 / 19$ or $21 \%$ of animals), so we cannot attribute this defect to a spontaneous mutation arising in a single population in transit. We have not observed such morphological defects in the original strain bearing $q y 78$, nor in any other strain we have studied. The lim-7p::ced-1::GFP transgene seems to sensitize worms for gonad morphology defects.

Whether or not overexpressed CED-1::GFP also disrupts the localization of untagged innexin proteins or other endogenous sheath membrane proteins as it does the tagged mKate::INX-8, and whether such disruption explains the gonad migration defects we observe for this allele, we currently cannot say. In many of these $q y 78$; lim-7p::ced-1::GFP coexpressing animals (strain DG5131), the intensity of CED-1::GFP is notably low (Figure 4D). Lower expression levels of the CED-1::GFP fusion protein, with or without $q y 78$ in the background, appear more likely to reveal the distal Sh1 cell. This could either be because the absence of competing bright signal makes it easier to detect dimly expressing distal Sh1, or because high levels of the transgene product are not tolerated in the distal Sh1 cell. The overexpression of the functional cell death receptor CED-1, and not just the overexpressed membrane-localized GFP, could also contribute to the defects observed in this strain. We sometimes observe abnormal sheath membrane protrusions that may result from aberrant engulfment of distal germ cells by the sheath (Figure 4E).

The discrepancy in apparent Sh1 position when two Sh1 cells express different amounts of CED$1::$ GFP and when of CED-1::GFP is coexpressed with mKate::INX-8 provides definitive evidence that CED-1::GFP sometimes fails to label the entire distal sheath (the same phenomenon is reported in Figure 2 Figure Supplement 2B in the recent study (Tolkin et al., 2021)). Furthermore, the defects caused in gonads overexpressing this functional cell death receptor suggests its localization to the Sh1 membrane at high levels is not well-tolerated. We therefore conclude that lim-7p::ced-1::GFP is an unacceptable marker of distal Sh1.

\section{Assessing sheath markers for evidence of gonad disruption-Brood size} Just because lim-7p::ced-1::GFP is a poor marker of the distal sheath does not, however, relieve concerns that the endogenously tagged innexins mKate::INX-8 and GFP::INX-9 are altering the gonad. A control for tagged innexin function was originally carried out (Gordon et al., 2020). Briefly, a careful genetic analysis (Starich et al., 2014) reported that the single mutant inx-9(ok1502) is fertile, but the inx-8(tn1474); inx-9(ok1502) double mutant is sterile. Therefore, attempts to use CRISPR/Cas9 introduce a fluorescent tag in the inx-8 locus were first performed in the inx-9(ok1502) background, and only once a fertile edited strain was recovered was the same edit introduced into the otherwise wild-type genetic background. We conducted brood size assays for strains discussed in this study, including the DG5131 strain containing both lim-7p:::ced-1::GFP and the tagged innexin qy78[mKate:::inx-8] that was imaged and analyzed by (Tolkin et al., 2021) but not assayed for brood size (Table 1). 
Table 1. Brood size assays.

\begin{tabular}{|c|c|c|c|c|}
\hline Full genotype & $\begin{array}{l}\text { Strain } \\
\text { name }\end{array}$ & Brood Size $^{a}$ & $\begin{array}{l}\text { Reduction } \\
\text { vs. N2 (\%) }\end{array}$ & $\begin{array}{l}\text { Embryonic } \\
\text { Lethality } \\
(\%)\end{array}$ \\
\hline wild type & N2 & $295 \pm 39(n=57)$ & NA & $N A^{b}$ \\
\hline $\begin{array}{l}\text { inx-9(qy79[GFP::inx- } \\
\text { 9]);nasi2c }{ }^{*}\end{array}$ & KLG019 & $226 \pm 22(n=13)$ & $23 \%$ & $41 \pm 8 \%$ \\
\hline $\begin{array}{l}\text { inx-8(qy78[mKate::inx- } \\
\text { 8);cpls } 122^{*}\end{array}$ & NK2571 & $220 \pm 41(n=15)$ & $25 \%$ & $8 \pm 5 \%$ \\
\hline $\begin{array}{l}\text { bcls39[lim-7p::ced- } \\
\text { 1::GFP];nals37* }\end{array}$ & DG5020 & $202 \pm 29(n=12)$ & $32 \%$ & $20 \pm 14 \%$ \\
\hline $\begin{array}{l}\text { inx-8(qy78[mKate::inx- } \\
\text { 8]);bcls39[lim-7p::ced- } \\
1:: G F P] ; n a l s 37^{*}\end{array}$ & DG5131 & $187 \pm 45(n=14)$ & $37 \%$ & $18 \pm 11 \%$ \\
\hline $\begin{array}{l}\text { cam-1(cp243[cam- } \\
1:: m N G])\end{array}$ & LP530 & $260 \pm 31(n=10)$ & $12 \%$ & NA \\
\hline ina-1(qy23[ina-1::mNG]) & NK2324 & $237 \pm 37(n=8)$ & $20 \%$ & NA \\
\hline
\end{tabular}

216

217

218

219

220

221

222

223

224

225

226

227

228

229

230

231

232

233

234

235

236

237

238

239

240

241

242

243

244

245

246

247

248

249

250

251

aViable offspring that hatch from a single parent

bN2 numbers come from multiple trials, not all of which counted negligible numbers of dead embryos, including the trial in which ina-1(qy23) and cam-1(cp243) were counted.

${ }^{c}$ qy79[GFP::inx-9] allele in strains NK2572 and NK2573 from (Gordon et al., 2020) with germ cell nuclear marker naSi2; this combination of alleles was used in the cross to glp-1(bn18) in Figure 1D. *full transgene descriptions in Methods for germ cell (naSi2) and DTC (cpls122, nals37) markers

We find reductions in brood size for all of the strains under investigation, including a reduced brood size and high embryonic lethality in two strains (DG5020 and DG5131) carrying the lim-7p::ced$1::$ GFP transgene. Interestingly, despite being genetically redundant genes (Starich et al., 2014) tagged in highly similar ways, and having similar live brood sizes, our endogenously tagged inx8(qy78) and inx-9(qy79) strains had dramatically different degrees of embryonic lethality, with qy79 producing over 150 unhatched eggs per worm.

Recent work describes brood sizes for a strong loss of function inx-8 allele in the inx-9(ok1502) mutant background (brood size of 0 ), and its suppressors, which range from minor rescue from complete sterility to near wild-type brood sizes (Starich and Greenstein, 2020). This work refers to brood sizes of $256+/-51$ as "nearly wild-type". Based on this threshold, we make the assessment that all of the fluorescently marked strains have mildly to moderately reduced brood sizes. On the basis of brood size alone, there is not a strong reason to prefer one of these markers over another.

Notably, the more severe brood size defect and high incidence of embryonic lethality observed by (Tolkin et al., 2021) for inx-8(qy78) were not observed either in this brood size assay, nor in prior ones conducted in our lab, nor during routine work with this allele over the past several years. However, the DG5131 strain combining qy78 with lim-7p::ced-1::GFP did have a more severe brood size defect and greater embryonic lethality than the parent $q y 78$ strain (15\% reduction), further suggesting that the defects observed for the qy78 allele by (Tolkin et al., 2021) depend strongly on the presence of the lim-7p::ced-1::GFP in the genetic background.

\section{Assessing sheath markers for evidence of gonad disruption-Proliferative zone}

Because brood size is an emergent property of many gonad, germline, embryonic, and systemic processes (including gonadogenesis, stem cell maintenance, regulation of meiosis, spermatogenesis, oogenesis, metabolism, ovulation, and embryogenesis), defects in brood size are not a direct proxy for dysregulation of the germ line proliferative zone. We therefore turned our attention back to the distal gonad and asked whether the strains with fluorescent sheath markers have abnormalities in the 
length of their proliferative zones (as measured by DAPI staining of germ cell nuclei to detect and measure the length of the germ line distal to crescent shaped nuclei of meiosis I, (Hubbard, 2007)) (Figure 5). The strain with the tagged innexin inx-8(qy78) and DTC marker shown in previous figures has a normally patterned distal germ line (average length of $111 \mu \mathrm{m}$, or $\sim 22$ germ cell diameters) that is indistinguishable from wild type N2 (Figure 5A, B, and E). Excluding worms with gross morphology defects, the DG5020 strain bearing a DTC marker and lim-7p::ced-1::GFP (Tolkin et al., 2021) also has a normal distal germ line (average of $98 \mu \mathrm{m}$, or $\sim 20$ germ cell diameters, a difference from wild type that is statistically but likely not biologically significant, Figure $5 \mathrm{C}$ and E). However, in the DG5131 strain that combines these alleles, the distal germ line is notably shortened (average of 68 $\mu \mathrm{m}$ or $\sim 13$ germ cell diameters, Figure $5 \mathrm{D}$ and $\mathrm{E})$. This is comparable to the $g / p-1(b n 18)$ allele at the permissive temperature shown in Figure 1E. Abnormal distal gonad patterning provides further evidence that a synthetic interaction between the lim-7p::ced-1::GFP transgene and the qy78 allelenot the $q y 78$ allele alone-is responsible for the shorter proliferative zone observed for strain DG5131 in a recent study (Tolkin et al., 2021).

In the end, we find that only the strain combining inx-8(qy78) and lim-7p::ced-1::GFP has a proliferative zone shorter than the wild-type. The moderate brood size defects shown by all strains could be caused by numerous processes outside of stem cell regulation. For example, we find the hypothesis of (Tolkin et al., 2021) based on the findings of (Starich et al., 2020, 2014), that a major role of inx-8/9 is in the proximal gonad regulating the provisioning of oocytes with essential metabolites, to be compelling. This hypothesis also has support from the large number of unhatched eggs observed for inx-9(qy79[GFP::inx-9]). Thus, we conclude with the observation that endogenous, fluorescently tagged sheath membrane proteins consistently mark both of the distal Sh1 cells without measurably impairing distal gonad function, and should be the reagents of choice for live-imaging in this cell type. They also consistently report a distal Sh1 position adjacent to the stem cell zone, as we previously found (Gordon et al., 2020).

\section{Discussion}

We discovered that the distal position of Sh1 is much closer to the distal end of the young adult hermaphrodite gonad then than was previously observed, where it forms an interface with the DTC's proximal projections and overlaps substantially with the proliferative zone of the germline where mitotic cell divisions occur (Gordon et al., 2020). We have now confirmed this finding with functional manipulations of germ cell cycling and cell fate. We observed a distal Sh1 position in other strains with endogenously tagged sheath cell membrane proteins that act in molecular pathways outside of gap junctional coupling, and in a substantial fraction of traditional transgenic animals expressing lim-7 promoter-driven CED-1::GFP, GFP::CAAX, and cytoplasmic GFP (though these strains have high variability in fluorescence intensity and localization). Therefore, we consider the results presented here to be confirmatory of the foundational finding of (Gordon et al., 2020), which is that almost all mitotic germ cells in the adult hermaphrodite contact the DTC or Sh1, with a noteworthy population in contact with both. Other recent work suggests a role for the sheath cells in promoting adult germ cell proliferation, specifically through modulation of Notch receptor glp-1 expression (Gopal et al., 2020). We focus especially on young adults in these studies (less than 24 hours post mid-L4, see Methods). An important caveat to the work is that the gonad is dynamic and cell shapes and positions change over time. Indeed, dynamic processes could lead to the surprising difference in position often seen between the two Sh1 cells in a single gonad arm, with one Sh1 cell growing more actively over germ cells as they leave the niche. The high variability of an overexpressed lim-7p::ced-1::GFP transgene has allowed for this surprising discovery, though that variability makes it a poor marker of the absolute position of the Sh1 cells, and it sometimes causes gonad defects.

In physics, the observer effect states that it is impossible to observe a system without changing it. In biological imaging in $C$. elegans, this means that we can either observe wild-type animals that are dead, dissected and/or fixed and coated or stained, or we can observe genetically modified animals that are alive. Some fine, membranous cellular structures do not survive fixation (Gerdes et al., 2013; Kornberg and Roy, 2014). On the other hand, any genomic modification runs the risk of altering an animal's physiology. 
We feel most confident examining endogenously tagged gene products for several reasons. First, proteins expressed at physiological levels are less likely to directly damage a cell vs. overexpressed fluorescent proteins (Kintaka et al., 2016). Second the ability to cross-reference among strains with different tagged proteins that act in different molecular pathways allows us to use concordant results in reconstructing cell positions; any single marker may or may not localize to the region of interest, but concordant results among independent experiments help construct an accurate picture of the cell. One factor to consider, however, is that not every endogenously expressed protein is likely to localize evenly across all regions of a cell. We would expect in a large cell like Sh1 that interacts with germ cells in many stages of maturation that some cell-surface proteins would be regionalized (and indeed we occasionally see a pattern suggestive of a diffusion barrier in the membrane of Sh1, Figure 2 Supplement $1 \mathrm{G}$ ). Along those lines, it seems likely that the Sh1 cells might have mechanisms to exclude the cell death receptor CED-1 from the cell membrane domain that contacts proliferating germ cells. The bcls39 transgene is typically used to study engulfment of apoptotic germ cell corpses at the proximal end of Sh1 and rescues ced-1 loss of function mutants for apoptotic germ cell corpse engulfment (Zhou et al., 2001). We find this marker to be unreliable in the distal region of the cell, and to cause gonad defects especially but not only when combined with endogenously tagged inx8(qy78). A recent study (Tolkin et al., 2021) uses this transgene in all of the backgrounds analyzed (sometimes detecting the CED-1::GFP by anti-GFP antibody staining, which appears to amplify the variability of the marker), so we find this problematic reagent to undermine that study's conclusions.

The need for caution when observing and interpreting endogenously tagged fluorescent proteins is noted. Several steps can and should be taken to increase confidence that a tagged protein is not causing cryptic or unwanted phenotypes. First, multiple edited lines should be recovered and outcrossed, thereby reducing the likelihood that a phenotype is caused by off-target Cas 9 cutting creating lesions in any individual edited genome. Second, brood size should be estimated either by timed food depletion (less rigorous) or formal brood size assays (more rigorous). Third, edited lines should be examined for known phenotypes caused by loss of function of the targeted genes. This can be done, in order of least to most rigorous, by consulting the literature, by comparing to RNAi treatments or known mutants, and finally by introducing AID tags and using the degron strategy to deplete the gene product under the lab's exact experimental conditions of choice (Zhang et al., 2015), however this step will not work for extracellular tags. Finally, any "markers" used should be assessed on their own for the phenotype of interest. Even with these controls in place, synthetic interactions can emerge between "markers" and alleles, including tagged proteins of interest. These interactions can themselves reveal biologically relevant phenomena, but only if they are recognized.

In the end, no transgenic or genome-edited strain is wild type, and it should be our expectation that such strains might be somewhat sensitized as a result. The perfect reagent does not exit. Therefore, we trust congruent results among a set of independent reagents with non-overlapping weaknesses. Finally, we can formulate questions narrowly enough that, despite their shortcomings, our imperfect reagents are adequate to help answer them. In the future, new endogenously tagged alleles that are expressed in the sheath, single-copy, membrane-localized transgenes that do not affect distal gonad patterning, and different imaging modalities like electron microscopy will shed more light on the complex relationship between the gonadal sheath and the germ line. At the present time, however, we consider the existence of an interface between the DTC and Sh1 cells that coincides with the boundary of the distal-most stem-like germ cells to be supported by the preponderance of evidence.

\section{Acknowledgements}

We thank T. Tolkin, A. Mohammed, T. Starich, T. Schedl, J.A. Hubbard, and D. Greenstein for sharing their manuscript and strains DG5020 (combining published alleles bcls39 (Zhou et al., 2001), and nals37 (Pekar et al., 2017) and DG5131 (combining published alleles qy78 (Gordon et al., 2020), bcls39 (Zhou et al., 2001), and nals37 (Pekar et al., 2017)). We thank D. Greenstein and the CGC for the temperature sensitive mutant strains and B. Goldstein for LP530. We are grateful for helpful conversations with $\mathrm{D}$. Sherwood and other colleagues. 


\section{References}

Cinquin O, Crittenden SL, Morgan DE, Kimble J. 2010. Progression from a stem cell-like state to early differentiation in the C. elegans germ line. Proc Natl Acad Sci U S A 107:2048-53. doi:10.1073/pnas.0912704107

Evans TC. 2006. Transformation and Microinjection In: WormBook, editor. The C. Elegans Research Community, WormBook.

Fox PM, Schedl T. 2015. Analysis of Germline Stem Cell Differentiation Following Loss of GLP-1 Notch Activity in Caenorhabditis elegans. Genetics 201:167-84. doi:10.1534/genetics.115.178061

Gerdes H-H, Rustom A, Wang X. 2013. Tunneling nanotubes, an emerging intercellular communication route in development. Mech Dev 130:381-387. doi:10.1016/J.MOD.2012.11.006

Gopal S, Amran A, Elton A, Ng L, Pocock R. 2020. Notch-Directed Germ Cell Proliferation Is Mediated by Proteoglycan-Dependent Transcription. bioRxiv 2020.07.30.229997. doi:10.1101/2020.07.30.229997

Gordon KL, Zussman JW, Li X, Martin CM, Sherwood DR. 2020. Stem cell niche exit in C. elegans via orientation and segregation of daughter cells by a cryptic cell outside the niche. Elife 9:e56383. doi:DOI: 10.7554/eLife.56383

Hall DH, Winfrey VP, Blaeuer G, Hoffman LH, Furuta T, Rose KL, Hobert O, Greenstein D. 1999. Ultrastructural features of the adult hermaphrodite gonad of Caenorhabditis elegans: Relations between the germ line and soma. Dev Biol 212:101-123.

Henderson ST, Gao D, Lambie EJ, Kimble J. 1994. lag-2 may encode a signaling ligand for the GLP1 and LIN-12 receptors of C. elegans. Development 120:2913-24.

Heppert JK, Pani AM, Roberts AM, Dickinson DJ, Goldstein B. 2018. A CRISPR Tagging-Based Screen Reveals Localized Players in Wnt-Directed Asymmetric Cell Division. Genetics 208:1147-1164. doi:10.1534/GENETICS.117.300487

Hubbard EJA. 2007. Caenorhabditis elegans germ line: a model for stem cell biology. Dev Dyn 236:3343-57. doi:10.1002/dvdy.21335

Killian DJ, Hubbard EJA. 2005. Caenorhabditis elegans germline patterning requires coordinated development of the somatic gonadal sheath and the germ line. Dev Biol 279:322-335. doi:10.1016/j.ydbio.2004.12.021

Kintaka R, Makanae K, Moriya H. 2016. Cellular growth defects triggered by an overload of protein localization processes. Sci Reports 2016 61 6:1-11. doi:10.1038/srep31774

Kornberg TB, Roy S. 2014. Cytonemes as specialized signaling filopodia. Development 141:729-36. doi:10.1242/dev.086223

Lee $\mathrm{CH}$, Shin H, Kimble J. 2019. Dynamics of Notch-Dependent Transcriptional Bursting in Its Native Context. Dev Cell 50:426-435.e4. doi:10.1016/j.devcel.2019.07.001

Oshima A, Tani K, Fujiyoshi Y. 2016. Atomic structure of the innexin-6 gap junction channel determined by cryo-EM. Nat Commun 7:13681. doi:10.1038/ncomms13681

Pekar O, Ow MC, Hui KY, Noyes MB, Hall SE, Jane Albert Hubbard E. 2017. Linking the environment, DAF-7/TGF $\beta$ signaling and LAG-2/DSL ligand expression in the germline stem cell niche. Dev 144:2896-2906. doi:10.1242/dev.147660

Schindelin J, Arganda-Carreras I, Frise E, Kaynig V, Longair M, Pietzsch T, Preibisch S, Rueden C, Saalfeld S, Schmid B, Tinevez J-Y, White DJ, Hartenstein V, Eliceiri K, Tomancak P, Cardona A. 2012. Fiji: an open-source platform for biological-image analysis. Nat Methods 9:676-682. doi:10.1038/nmeth.2019

Shin H, Haupt KA, Kershner AM, Kroll-Conner P, Wickens M, Kimble J. 2017. SYGL-1 and LST-1 link niche signaling to PUF RNA repression for stem cell maintenance in Caenorhabditis elegans. PLoS Genet 13. doi:10.1371/journal.pgen.1007121

Starich T, Greenstein D. 2020. A Limited and Diverse Set of Suppressor Mutations Restore Function to INX-8 Mutant Hemichannels in the Caenorhabditis elegans Somatic Gonad. Biomol 2020, Vol 10, Page 1655 10:1655. doi:10.3390/BIOM10121655

Starich TA, Bai X, Greenstein D. 2020. Gap junctions deliver malonyl-CoA from soma to germline to support embryogenesis in Caenorhabditis elegans. Elife 9. doi:10.7554/eLife.58619

Starich TA, Hall DH, Greenstein D. 2014. Two classes of gap junction channels mediate somagermline interactions essential for germline proliferation and gametogenesis in Caenorhabditis elegans. Genetics 198:1127-1153. doi:10.1534/genetics.114.168815 
417 Team RDC. 2020. R: A language and environment for statistical computing.

418 Tolkin T, Mohammed A, Starich T, Schedl T, Hubbard EJA, Greenstein D. 2021. Innexin function 419 dictates the spatial relationship between distal somatic cells in the Caenorhabditis elegans gonad without impacting the germline stem cell pool. bioRxiv 2021.10.22.465523. doi:10.1101/2021.10.22.465523

Zhang L, Ward JD, Cheng Z, Dernburg AF. 2015. The auxin-inducible degradation (AID) system enables versatile conditional protein depletion in C. elegans. Dev 142:4374-4384. doi:10.1242/dev.129635

Zhou Z, Hartwieg E, Horvitz HR. 2001. CED-1 Is a Transmembrane Receptor that Mediates Cell Corpse Engulfment in C. elegans. Cell 104:43-56. doi:10.1016/S0092-8674(01)00190-8 


\section{Methods}

Strains

In strain descriptions, we designate linkage to a promoter with a $p$ following the gene name and designate promoter fusions and in-frame fusions with a double semicolon (::). Some integrated strains (xxls designation) may still contain for example the unc-119(ed4) mutation and/or the unc-119 rescue transgene in their genetic background, but these are not listed in the strain description for the sake of concision, nor are most transgene 3' UTR sequences. Strains are as follows:

NK2571 (inx-8(qy78[mKate::inx-8]) IV; (cpls122[lag-2p::mNeonGreen:: PLC $\left.{ }^{\delta P H}\right]$ ), KLG019 (inx9(qy79[GFP::inx-9]); (naSi2(mex-5p::H2B::mCherry::nos-2 3'UTR) II, LP530 (cam-1(cp243[cam1::mNG-C1^3xFlag), NK2324 (ina-1(qy23[ina-1::mNG] III), tnls6[lim-7p::GFP + rol686 6(su1006)] X, DG5020 (bcls39[lim-7p::ced-1::GFP + lin-15(+)] V; nals37llag-2p::mCherry:: plcdeltaPH + unc119(+)]; DG5131 (inx-8(qy78[mKate::inx-8]) IV bcls39[lim-7p::ced-1::GFP + lin-15(+)] V; nals37[lag2p::mCherry:: plcdeltaPH + unc-119(+)];KLG020 (rlmls5[lim-7p::GFP::caax]; cpls91[lag-2p::2x mKate2::PLCdPH::3xHA::tbb-2 3'UTR LoxN] II))

\section{Staging of animals for comparisons among sheath markers} We focused on young adult animals around the time egg laying commences, as in (Gordon et al., 2020). Mid L4 animals are picked from healthy, unstarved populations (which are maintained without starving for the duration of the experiment). These animals are kept at $20^{\circ} \mathrm{C}$ for $16-18$ hours, until adulthood is reached and ovulation begins. We prefer not to age the animals much farther into adulthood for routine imaging (though we did this for the temperature shift experiments to follow previously published experimental regimes), as once a full row of embryos is present in the uterus, the distal gonads can become compressed or obscured by embryos. For strains in which a gonad migration defect is observed (DG5020, DG5131), picking animals in the L4 stage prevents bias for or against normal-looking adults (as the defects are profound enough to be visible on the dissecting scope in adults).

\section{Temperature-sensitive mutant analysis}

Worms from the emb-30(tn377) mutant genotype were grown at the permissive temperature $\left(16^{\circ} \mathrm{C}\right)$ for $24 \mathrm{~h}$ past L4. Plates were shifted to the restrictive temperature $\left(25^{\circ} \mathrm{C}\right)$ for $15 \mathrm{~h}$ before DAPI staining, while permissive-temperature controls were maintained at $16^{\circ} \mathrm{C}$ for $18 \mathrm{~h}$ before staining (because development is proportionally slower at $16^{\circ} \mathrm{C}$ than at $25^{\circ} \mathrm{C}$, permissive-temperature controls were cultured longer).

Worms from the glp-1(bn18) mutant genotype were grown at the permissive temperature of $16^{\circ} \mathrm{C}$ for $24 \mathrm{~h}$ past $L 4$. Plates were shifted to the restrictive temperature $\left(25^{\circ} \mathrm{C}\right)$ for $6 \mathrm{~h}$ (Fox and Schedl, 2015). Permissive-temperature controls were maintained at $16^{\circ} \mathrm{C}$ for $6 \mathrm{~h}$. Worms were imaged live (see Confocal imaging, below).

\section{DAPI staining}

DAPI staining was done according to standard protocols, with the cold methanol fixation done for 2.5 minutes and the concentration of DAPI at $10 \mathrm{ug} / \mathrm{ml}$ in distilled water in the dark for five minutes, washed with $0.1 \%$ Tween in PBS. Samples were briefly stored at $4^{\circ} \mathrm{C}$ in $75 \%$ glycerol and imaged directly in glycerol.

\section{Confocal imaging}

All images were acquired on a Leica DMI8 with an xLIGHT V3 confocal spinning disk head (89 North) with a 63x Plan-Apochromat (1.4 NA) objective and an ORCA-Fusion Gen-III sCMOS camera (Hamamatsu Photonics). RFPs were excited with a $555 \mathrm{~nm}$ laser, GFPs were excited with a $488 \mathrm{~nm}$ laser, and DAPI was excited with a $405 \mathrm{~nm}$ laser. Worms were mounted on agar pads with $0.01 \mathrm{M}$ sodium azide (live) or in $75 \%$ glycerol (DAPI stained).

\section{Fluorescence intensity of lim-7p::CED-1::GFP and mKate::INX-8}

For quantitative comparisons of fluorescence intensity shown in Figure 3 and Figure 4, gonads were imaged with uniform laser power and exposure times with 1 micron Z-steps. Images were opened in 
FIJI (Schindelin et al., 2012) and z-projections were made through the depth of the superficial half of the gonad (not including signal from the deep Sh1 cell if it was present). Images without any detectable Sh1 expression were discarded (2/32 images from the analysis in Figure 3A). A line 20 $\mu \mathrm{m}$ long parallel to long axis of the gonad, terminating near the distal boundary of GFP expression, and not crossing any gaps in Sh1 revealing background was drawn, and average fluorescence intensity was measured along its length in arbitrary units.

\section{Measurements of DTC and Sh1 positions}

The distal tip of the gonad was identified in the fluorescence images if the DTC was marked or in a DIC image if the DTC was not marked in a given strain. The distance from the gonad tip to the longest DTC process (when marked), and from the gonad tip to the most distal extent of Sh1 was measured in FIJI (Schindelin et al., 2012). A DTC-Sh1 interface is detected by subtracting the first value from the second value-negative numbers reflect the amount of overlap of these cellular domains across the germ line, positive numbers reflect a gap. This is a conservative estimate, as a gap of less than one germ cell diameter $(\sim 5 \mu \mathrm{m})$ would still allow germ cells to contact both the DTC and Sh1 at the same time. Min/max settings on the fluorescence images are adjusted to allow the faintest signal to be detected when measuring.

\section{Analysis of mosaic expression}

The variability of the lim-7p::ced-1::gfp transgene allowed us to distinguish the two Sh1 cells in a pair, especially when coexpressed with qy78[mKate::inx-8]. For this experiment, we imaged animals through the full thickness of the distal gonad ( $40 \mu \mathrm{m}$ instead of our usual $20 \mu \mathrm{m}$ that captures just the superficial half of the gonad that can be imaged more clearly). Animals in which two distinct Sh1 cells had different levels of GFP signal were analyzed further for relative cell position. For DG5131, this was $6 / 19$ samples. For DG5020, this was 31/53 samples.

\section{Brood size assays}

DG5020 and DG5131 were shipped overnight on 9/23, passaged off the starved shipment plate onto fresh NGM+OP50 plates and maintained by passaging unstarved animals for 3 generations before beginning the brood size assay. For each strain, 10-15 L4 animals were singled onto NGM plates seeded with OP50 and kept in the same incubator, on the same shelf, at $20^{\circ} \mathrm{C}$. The singled animals were passaged once per day on each of the following 5 days to fresh plates, with all plates maintained at $20^{\circ} \mathrm{C}$. Two days after removing the parent, the plates with larval offspring were moved to $4^{\circ} \mathrm{C}$ for 20 minutes to cause worm motion to cease, and all larvae (and unhatched eggs when noted) were counted on a dissecting scope with a clicker by the same team of worm counters, with internal controls. Plates with unhatched eggs were examined and recounted one day later to see if any hatched. Offspring from parent worms that died or burrowed in the process were not counted. Total sample sizes and results reported in Table 1.

\section{Distal germ line patterning}

Measurements were made from the distal end of the gonad to the transition zone, which is the distalmost row of germ cells with more than one crescent-shaped nucleus.

\section{Statistical analyses}

Tests, test statistics, and $p$ values given for each analysis in the accompanying figure legends. Oneway ANOVA followed by Tukey's multiple comparisons test were conducted in R (R Team, 2020) or Prism (GraphPad Prism version 9.20 (283) for macOS, GraphPad Software, San Diego, California USA, www.graphpad.com.

\section{Figures and Figure Legends}

Table 1. Brood size assays. 
A
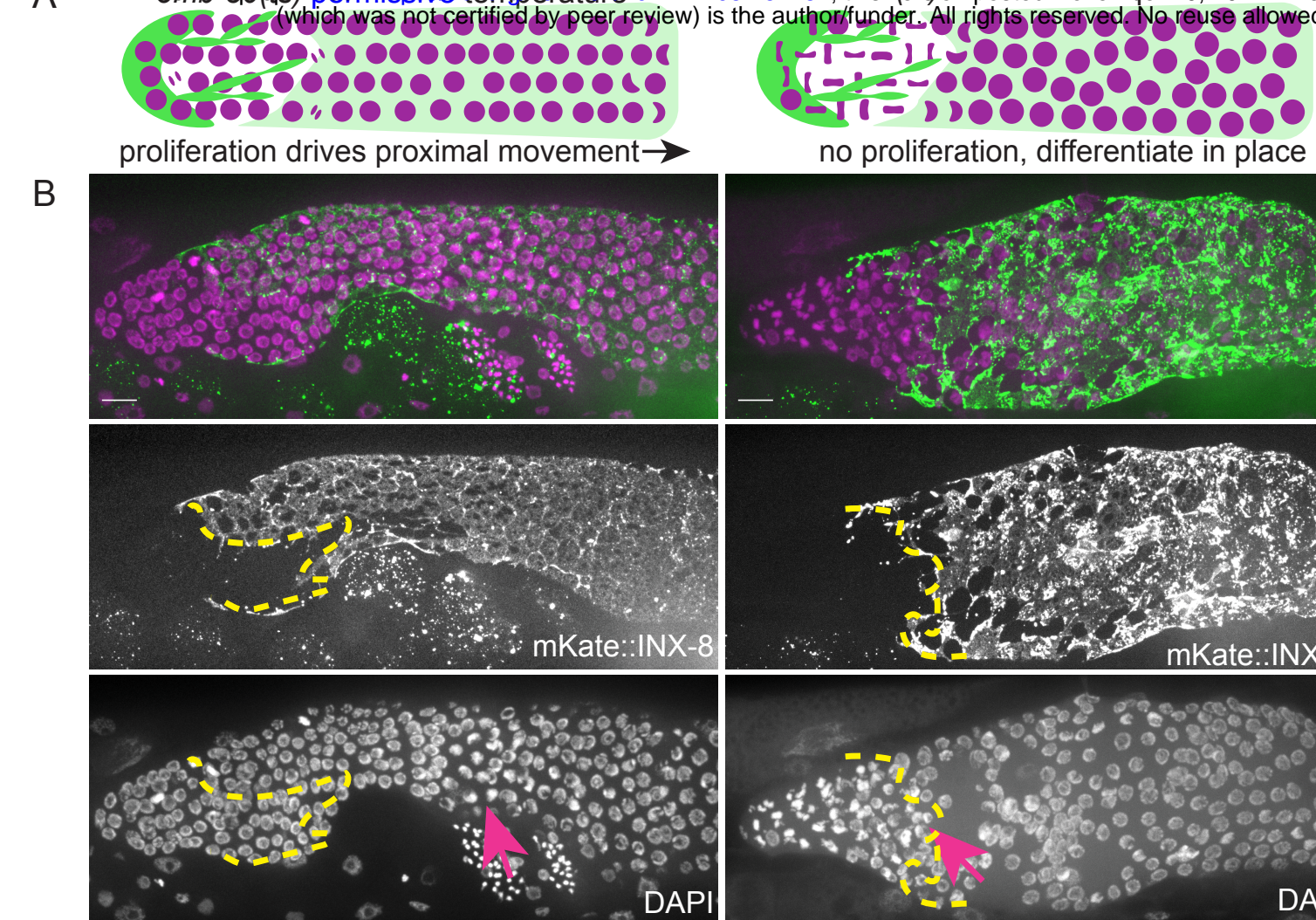

Figure 1

C

glp-1(ts) permissive temperature

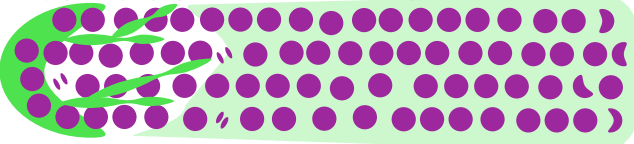

meiotic entry occurs at distance from DTC
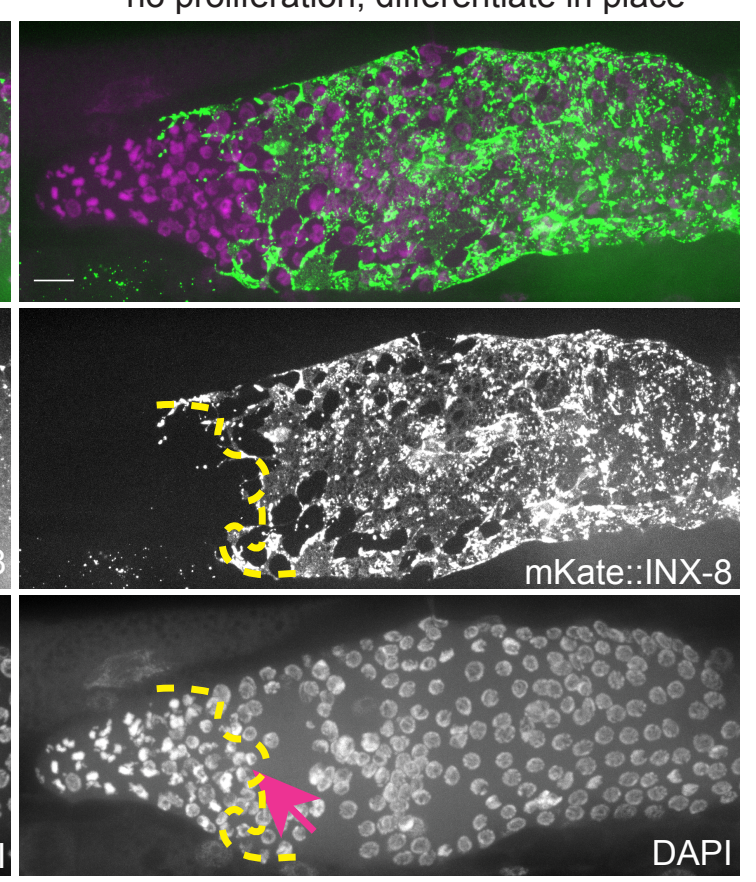

D

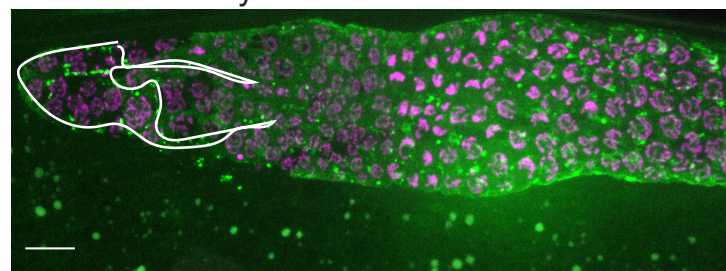

meiotic entry occurs first in cells under Sh1
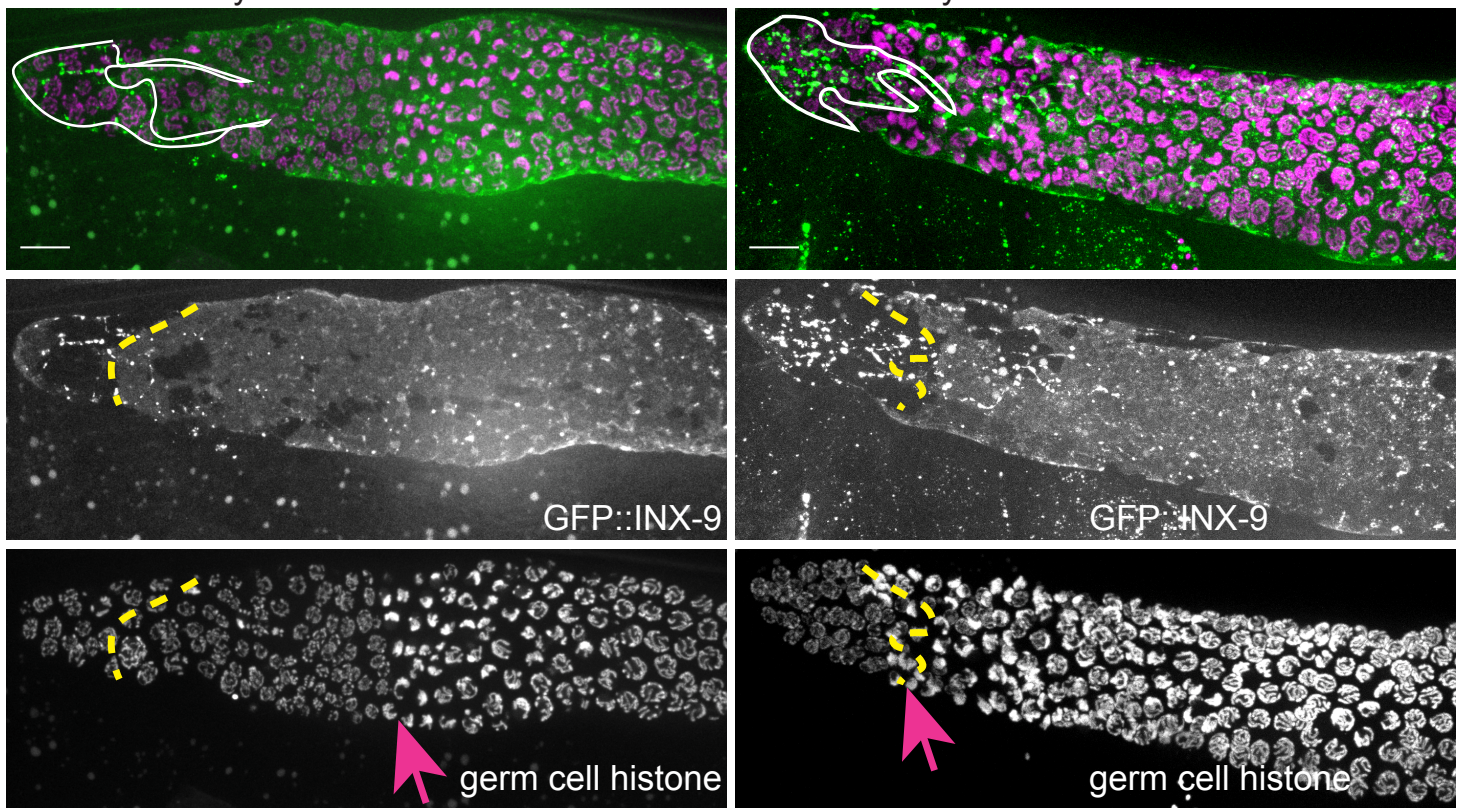

$$
\text { E }
$$
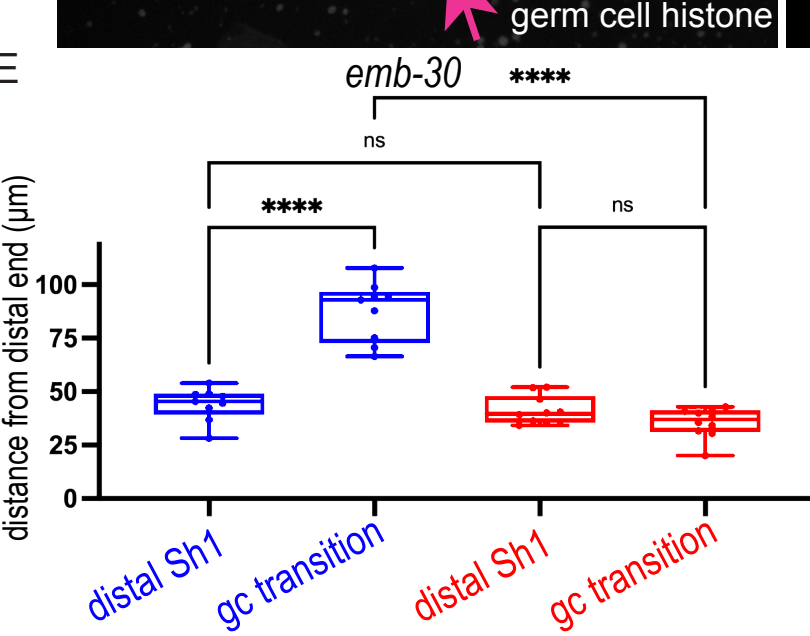
536 Figure 1. The Sh1 cells associate with proliferative germ cells that are on the path to

537 differentiation. (A) Schematic of hypothesis for emb-30(tn377) experiment. Germ cell (gc) nuclei shown in magenta, somatic gonad cells shown in green (DTC) and transparent green (Sh1). (B) Gonads from worms reared at permissive (left column) and restrictive (right column) temperatures. Top, merged image. Middle, mKate::INX-8 labeling Sh1 (edge outlined with yellow dashed line). Bottom, DAPI staining labeling all nuclei with pink arrow marking gc transition and same yellow dashed line as in middle image showing Sh1 edge. (C) Schematic of hypothesis for glp-1(ts) experiment. (D) Gonads from permissive (left column) and restrictive (right column) temperatures. Top, merged image. Middle, GFP::INX-9 labeling DTC (outlined in white) and Sh1 (edge outlined with yellow dashed line). Bottom, germ cell histone mCherry (naSi2[mex-5p::H2B::mCherry]) with pink

547

548

549

550

551

552

553

554

555

556

557

558

559

560

561

562

563

564

565

566 arrow showing gc transition and same yellow dashed line as in middle image showing Sh1 edge. Note that the glp-1(bn18) allele is not fully wild type at permissive temperatures and is known to have a shortened proliferative zone (Fox and Schedl 2015). (E) Box plots overlaid with all datapoints measuring the distal position of Sh1 and the position of the transition in germ cell nuclear morphology. Permissive temperature shown in blue; restrictive temperature shown in red. Permissive emb-30 N=9; restrictive emb-30 $\mathrm{N}=10$. Permissive glp-1 $\mathrm{N}=18$; restrictive $g / p-1 \mathrm{~N}=21$. A one-way ANOVA to assess the effect of temperature on proximodistal position of gonad features was performed, and was significant for emb-30: $F_{3,34}=63.00, p<0.0001$. Tukey's multiple comparison test found that the mean values of the positions of Sh1 and the germ cell transition were significantly different at the permissive temperature (mean difference of $-43.4 \mu \mathrm{m}, 95 \% \mathrm{Cl}-55.03 \mu \mathrm{m}$ to -31.77 $\mu \mathrm{m}, \mathrm{p}<0.0001$ ), but not at the restrictive temperature (mean difference of $5.64 \mu \mathrm{m}, 95 \% \mathrm{Cl} 5.393 \mu \mathrm{m}$ to $16.67 \mu \mathrm{m}, \mathrm{p}=0.520$ ). The position of the germ cell transition differed at the permissive vs. restrictive temperatures (mean difference of $51.96 \mu \mathrm{m}, 95 \% \mathrm{Cl} 40.63 \mu \mathrm{m}$ to $63.30 \mu \mathrm{m}, \mathrm{p}<0.0001$ ), but the Sh1 position did not (mean difference of $2.29 \mu \mathrm{m}, 95 \% \mathrm{Cl}-8.410 \mu \mathrm{m}$ to $14.26 \mu \mathrm{m}, \mathrm{p}=0.898$ ). Similar results were obtained for $g / p-1: F_{3,74}=52.84, p<0.0001$. Tukey's multiple comparison test found that the mean values of the positions of Sh1 and the germ cell transition were significantly different at the permissive temperature (mean difference of $-35.51 \mu \mathrm{m}, 95 \% \mathrm{Cl}-44.59 \mu \mathrm{m}$ to $-26.43 \mu \mathrm{m} \mathrm{p}<0.0001$ ) but not at the restrictive temperature (mean difference of $2.514 \mu \mathrm{m},-5.892 \mu \mathrm{m}$ to $10.92 \mu \mathrm{m}, \mathrm{p}=0.861$ ). The position of the germ cell transition differed at the permissive vs. restrictive temperatures (mean difference of $36.02 \mu \mathrm{m}, 95 \% \mathrm{Cl} 27.27 \mu \mathrm{m}$ to $44.77 \mu \mathrm{m}, \mathrm{p}<0.0001$ ), but the Sh1 position did not (mean difference of $-1.997 \mu \mathrm{m}, 95 \% \mathrm{Cl}-10.75 \mu \mathrm{m}$ to $6.753 \mu \mathrm{m}, \mathrm{p}=0.9318)$. All scale bars $10 \mu \mathrm{m}$. 
bioRxiv preprint doi: https://doi.org/10.1101/2021.11.08.467787; this version posted November 10, 2021. The copyright holder for this preprint (which was not certified by peer review) is the author/funder. All rights reserved. No reuse allowed without permission.
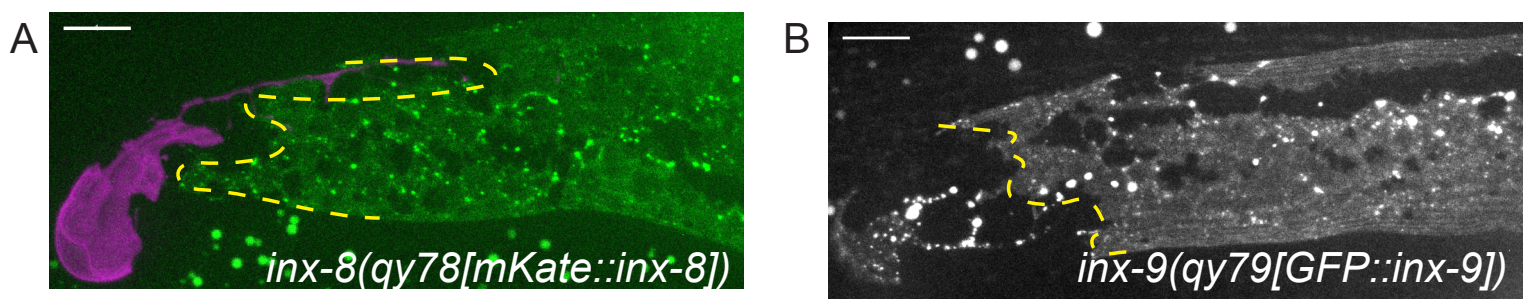

Figure 2
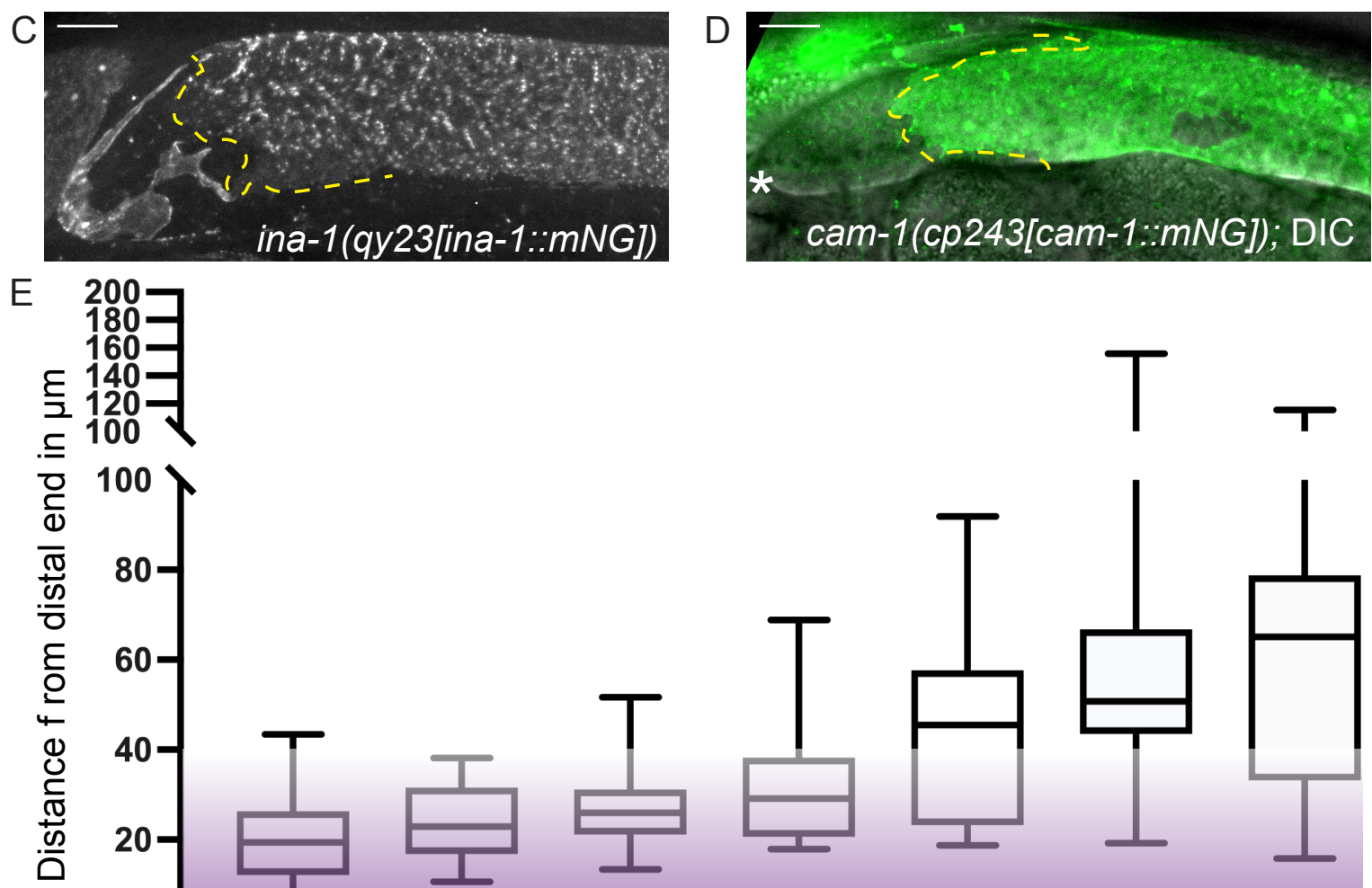

F

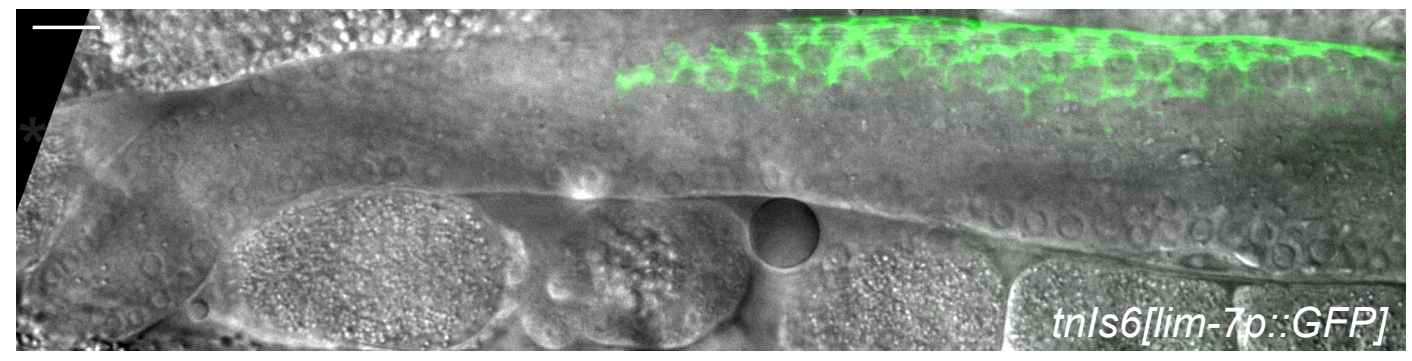

G

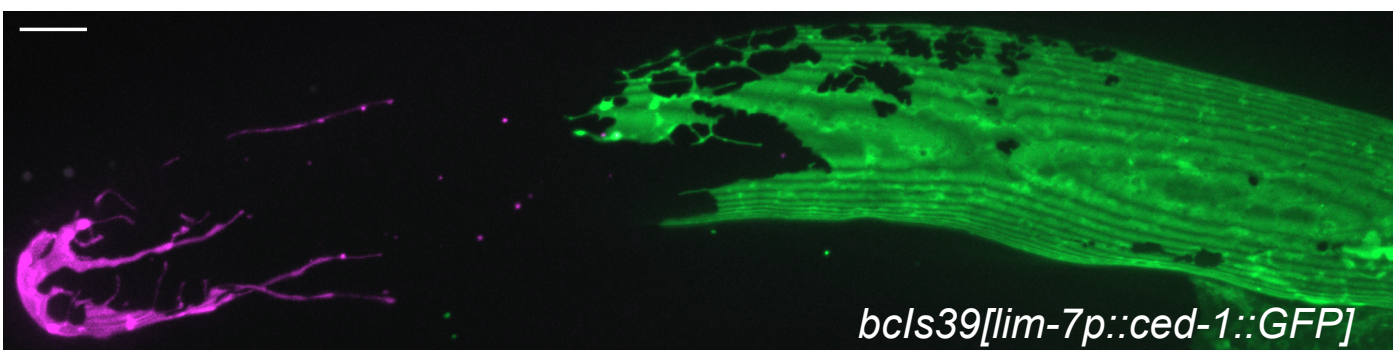

$\mathrm{H}$

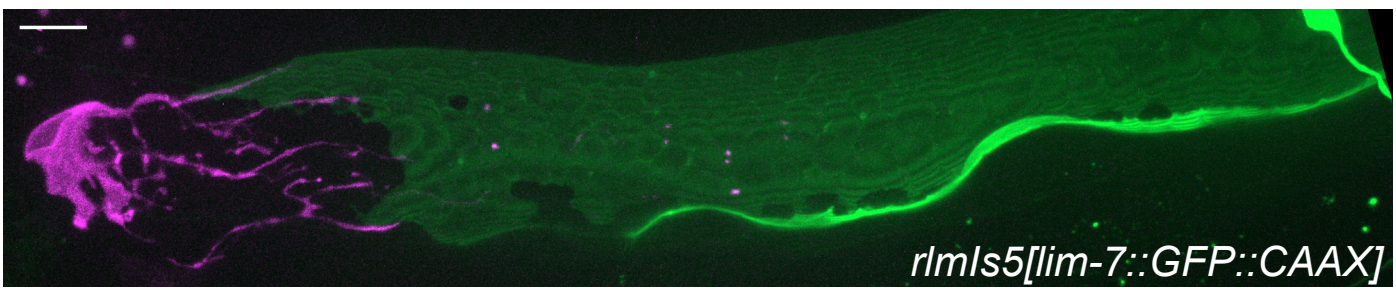


bioRxiv preprint doi: https://doi.org/10.1101/2021.11.08.467787; this version posted November 10, 2021. The copyright holder for this preprint (which was not certified by peer review) is the author/funder. All rights reserved. No reuse allowed without permission.

567

568

569

570

571

572

573

574

575
Figure 2. Sheath-expressed fluorescent proteins show consistency among endogenously tagged membrane proteins and greater variability in overexpressed transgenes. (A) qy78[mKate::INX-8]; cpls122[lag-2p::mNeonGreen:: PLC $\left.C^{\delta P H}\right] \mathrm{N}=21$ (B) qy79[GFP:::inx9] $\mathrm{N}=16$ (C) qy23[ina-1::mNG] $\mathrm{N}=26$ (D) cp243[cam-1::mNG] $\mathrm{N}=21$ (E) Box plots of Sh1 positions for all strains, including transgenes (F) tnls6[lim-7p::GFP] $\mathrm{N}=20$ (G) Strain DG5020 bcls39[lim-7p::CED-1::GFP]; nals37[lag-2p:::mCherry-PH]; $\mathrm{N}=52$ (note that mean and range agree with those reported in (Tolkin et al., 2021)) (H) rIm/s5[lim-7p::GFP::CAAX];cp/s122 N=21. Purple gradient marks approximate extent of stem cell zone (Lee et al., 2019; Shin et al., 2017).See Figure 2 Supplement 1 for images of minimum and maximum observed distances for all markers. All scale bars $10 \mu \mathrm{m}$. 
bioRxiv preprint doi: https://doi.org/10.1101/2021.11.08.467787; this version posted November 10, 2021. The copyright holder for this preprint (which was not certified by peer review) is the author/funder. All rights reserved. No reuse allowed without permission.

A

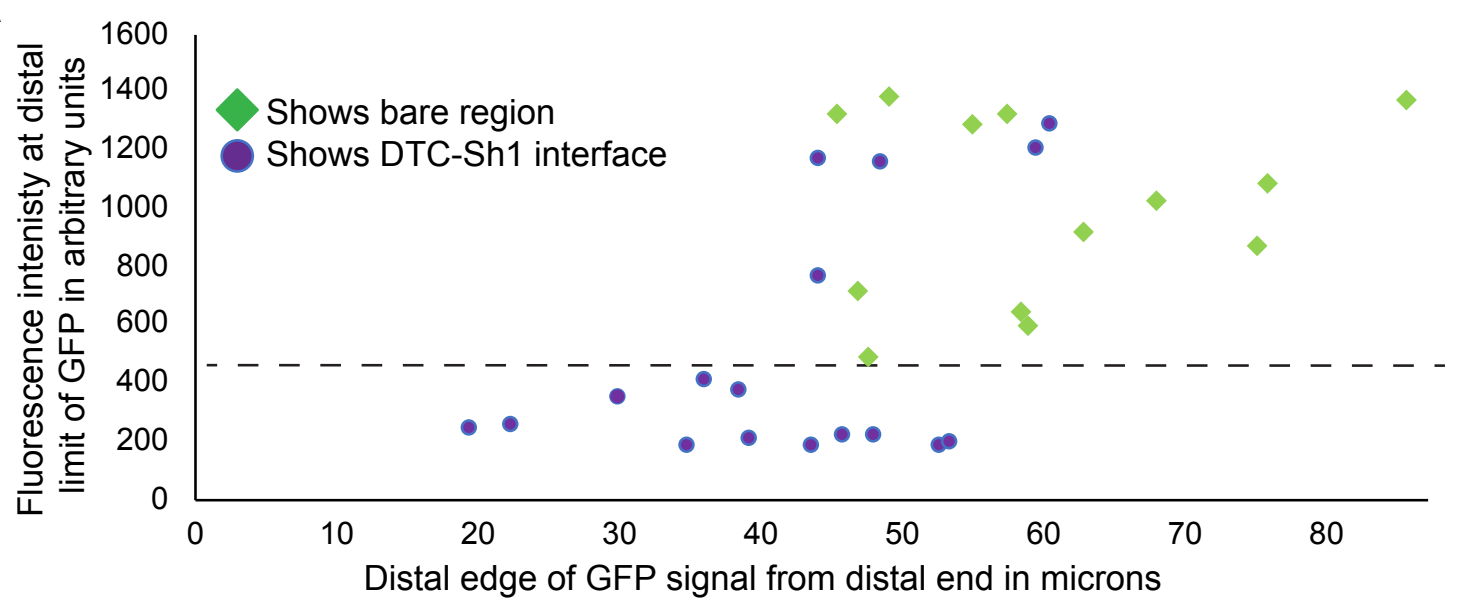

Figure 3

B

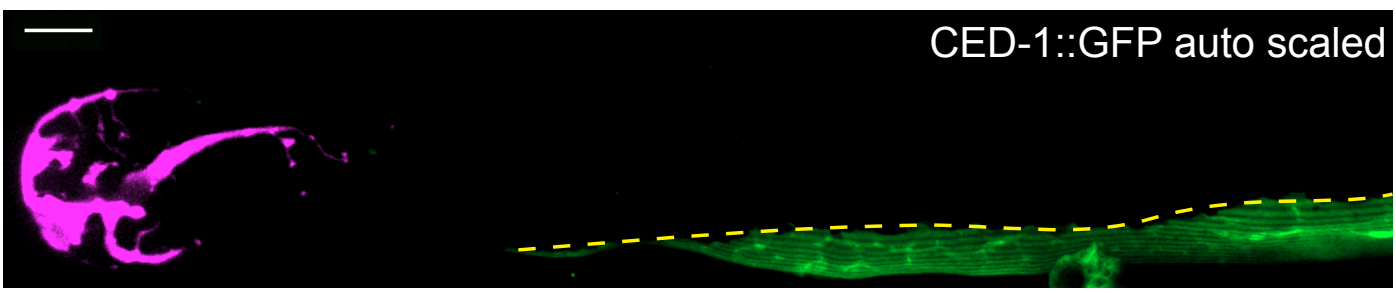

B'

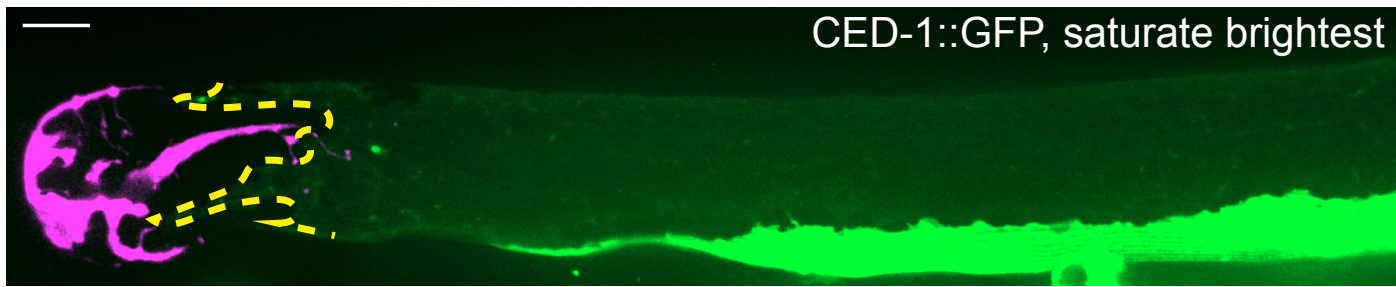

$\mathrm{C}$

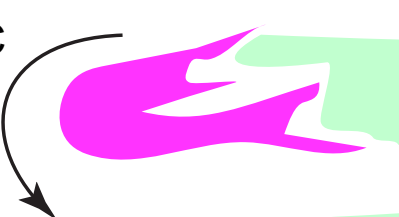

\section{Sh1a}

Sh1p

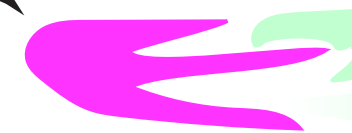

Sh1a

?

$$
\text { Sh1p }
$$

Sh1p

D

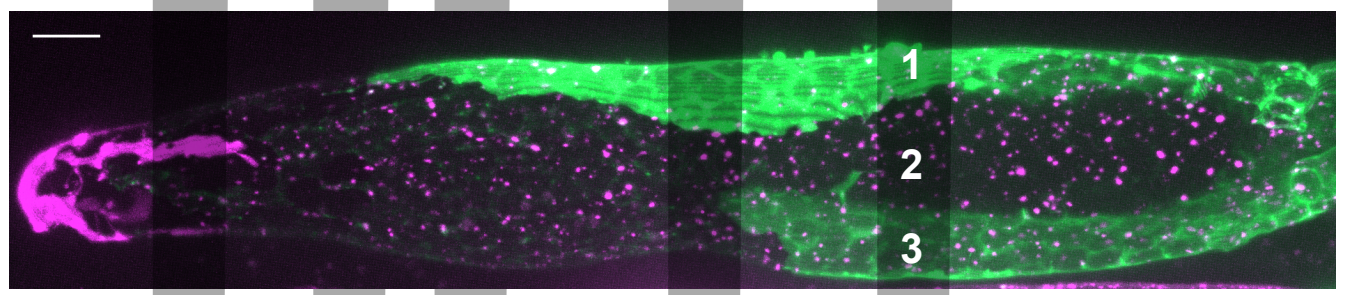

E
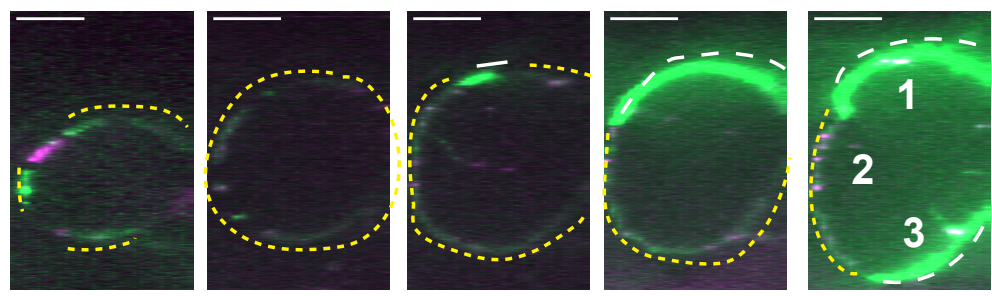

F

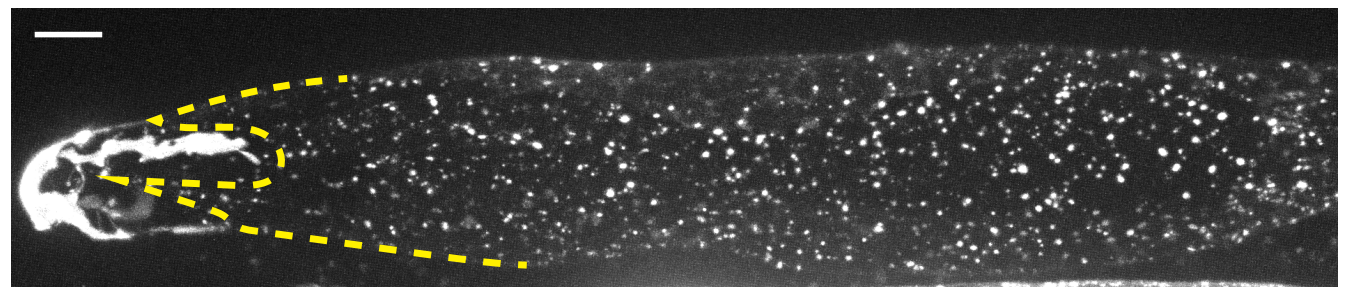


Figure 3. lim-7p::ced-1::GFP has variable expression intensity that conceals distal position of Sh1. (A) Plot of distal position vs. fluorescence intensity in arbitrary units of CED-1::GFP at the distal limit of its domain in lim-7p::ced-1::GFP DG5020 animals. Dashed black line: all of the lowlyexpressing gonads (under $\sim 400$ A.U., or $<30 \%$ maximum brightness of brightest sample) have a DTC-Sh1 interface detected. (B) DG5020 sample in which disparate expression levels in the two Sh1 cells of a single gonad arm obscure detection of the DTC-Sh1 interface. The GFP channel is scaled automatically in B; B' is scaled to saturate the brightest pixels and reveal the dim second Sh1 cell. (C) Schematic showing Sh1 pair configuration over distal germ line, with the distal extent of Sh1p uncertain in superficial projection. The two Sh1 cells of a pair descend from the anterior and posterior daughters of Z1 and Z4, so the two Sh1 cells are here labeled Sh1a and Sh1p (arbitrarily). Top, superficial view. Bottom, side view. (D) DG5131 Sample in which one Sh1 cell contacts the DTC around the circumference of the germ line and the other Sh1 cell lies at some distance from the distal end. Gray boxes and numbers mark planes and landmarks shown in (E). (E) Five cross sections through gonad in $(E)$ made by projecting through two $1 \mu \mathrm{m}$ re-slices at the positions shown by gray boxes in (D). (F) Same worm as in (D,E); endogenously tagged $m$ Kate::inx-8 more uniformly labels the Sh1 cells, obscuring their individual shapes. Same analysis for DG5020 shown in Figure 3 Supplement 1 . All scale bars $10 \mu \mathrm{m}$. 
bioRxiv preprint doi: https://doi.org/10.1101/2021.11.08.467787; this version posted November 10, 2021. The copyright holder for this preprint

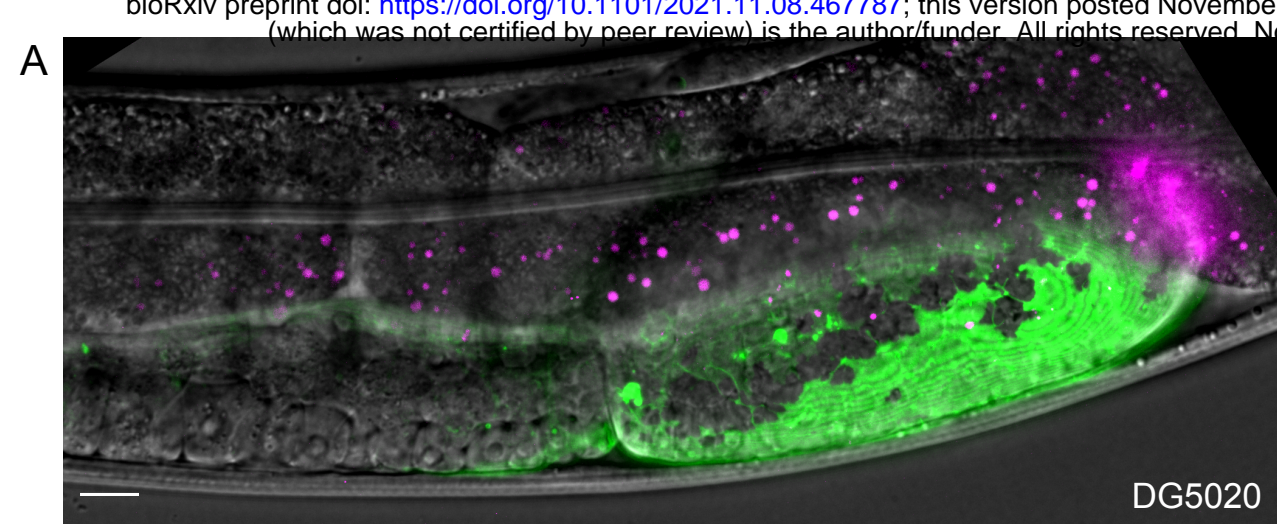

Figure 4

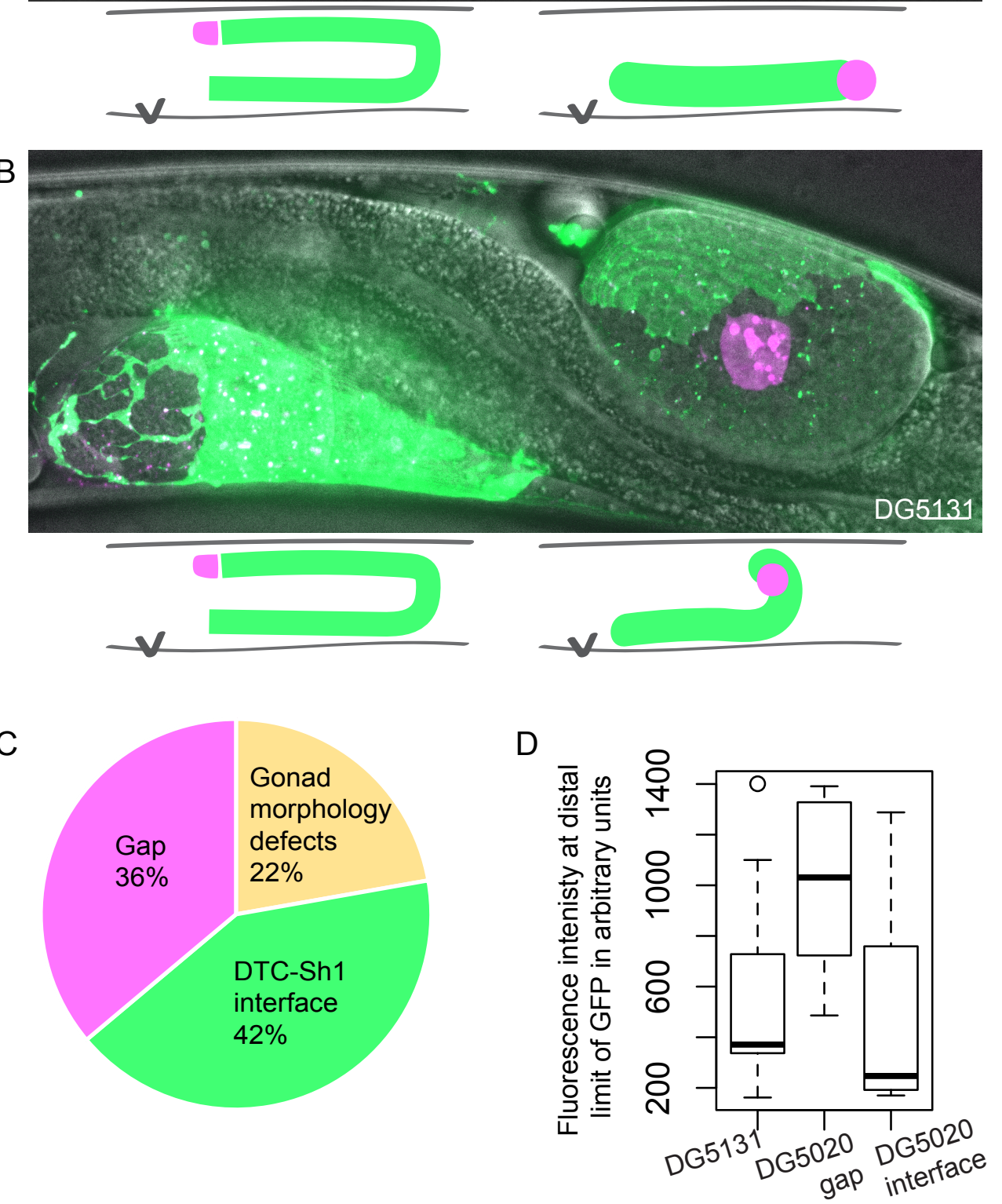

E

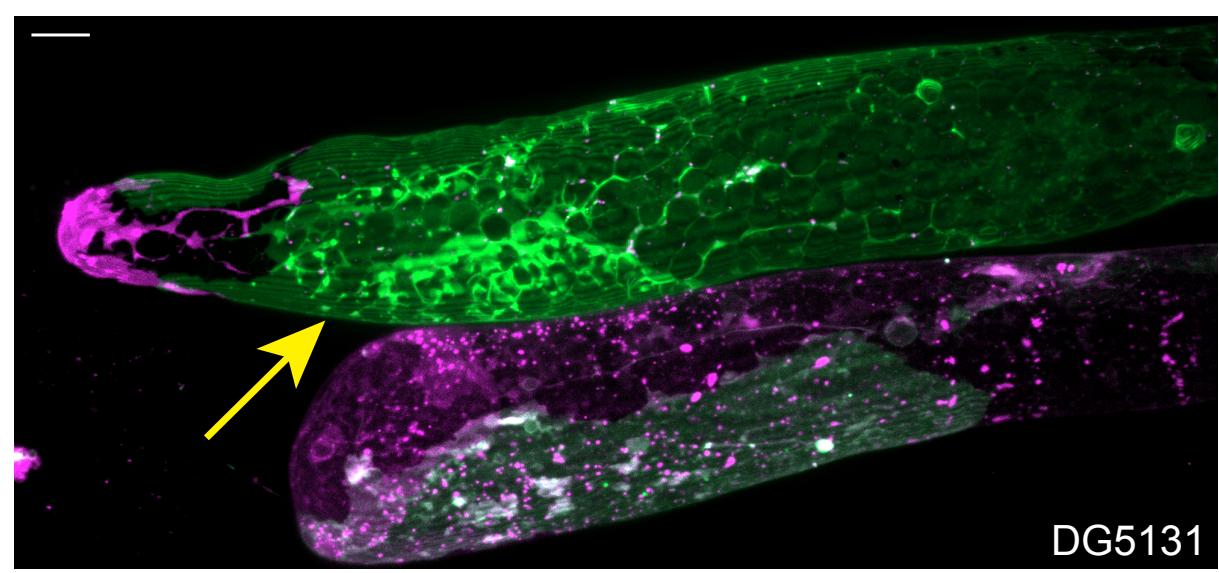


Figure 4. lim-7p::CED-1::GFP is correlated with gonad defects.

(A) Example of gonad morphology defect in DG5020 strain, in which the gonad failed to turn. (B) Example of gonad morphology defect in DG5131 strain, in which gonad turned once and arrested without elongating along the dorsal body wall. Schematics in A and B show wild-type gonad morphology with two turns and a DTC that arrives at the dorsal midbody, left, beside schematics of defective gonad migration shown in micrographs. (C) Relative proportions of phenotypes observed in DG5020 animals $(\mathrm{N}=72)$. (C) Boxplot comparing fluorescence intensity for coexpressing strain DG5131 in addition to data shown in Figure 3 for DG5020. Fluorescence intensity of the lim-7p::ced$1:: G F P$ transgene in this background is statistically indistinguishable from expression levels of this transgene in an otherwise wild type background in the subset of samples that display a DTC-Sh1 interface, shown here segregated from samples from this strain that show a gap between the DTC and Sh1 cells. DG5131 N=17. DG5020 gap N=13. DG5020 interface $N=17$. A one-way ANOVA to determine the effect of category (genotype or presence of an interface) and fluorescence intensity was performed and was significant, $F_{2,44}=7.70, p=0.001$ ). Tukey's multiple comparison test finds that the mean fluorescence intensity of DG5020 gonads with a DTC-Sh1 interface differs from DG5020 gonads with a gap between Sh1 and the distal end $(p=0.002)$ and does not differ from DG5131 worms ( $p=0.908)$. (G) Gonad from DG5131 strain with yellow arrow indicating aberrant engulfment of germ cells in the proliferative zone. All scale bars $10 \mu \mathrm{m}$. 
bioRxiv preprint doi: httos://doi.ora/10.1101/2021.11.08.467787: this version posted November 10.2021 . The copyright holder for this preprint

A

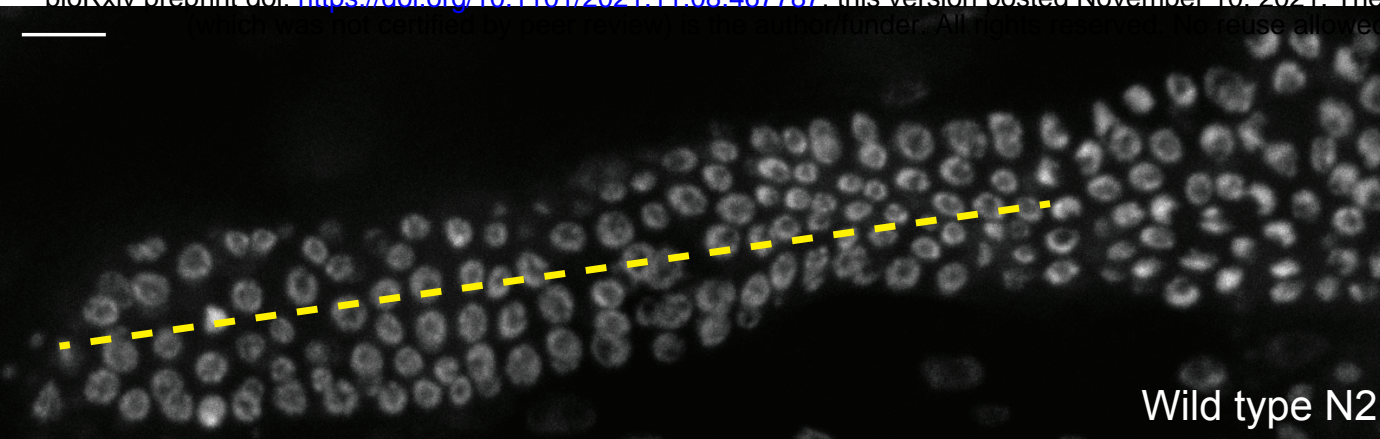

without permission 5

B

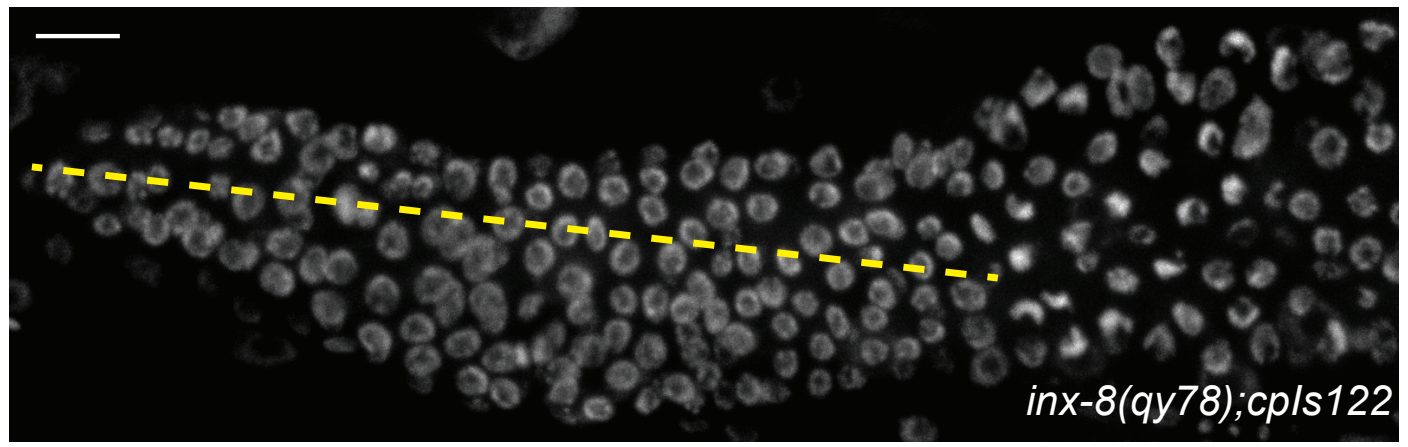

C

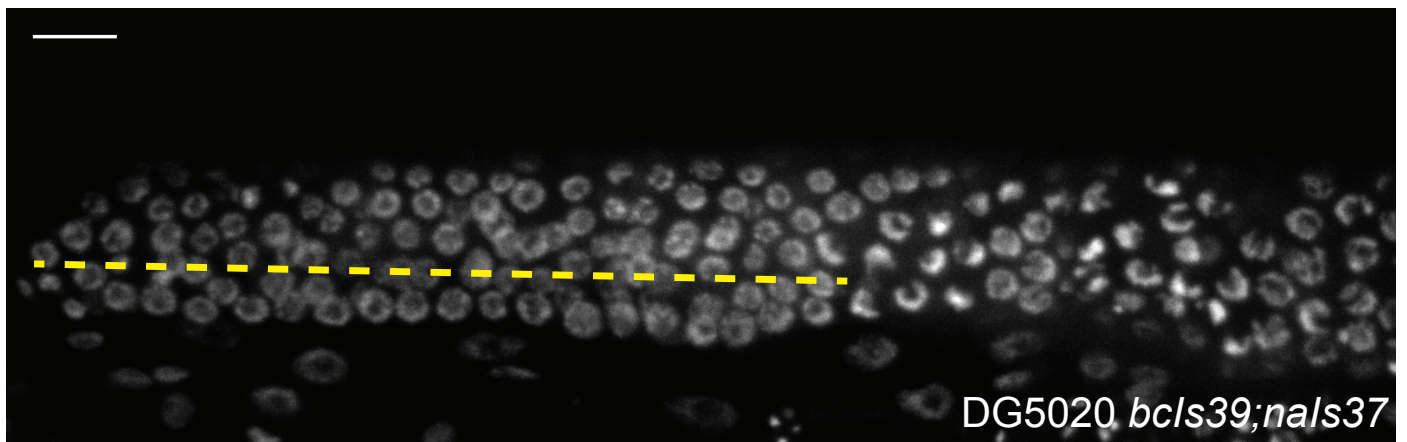

D

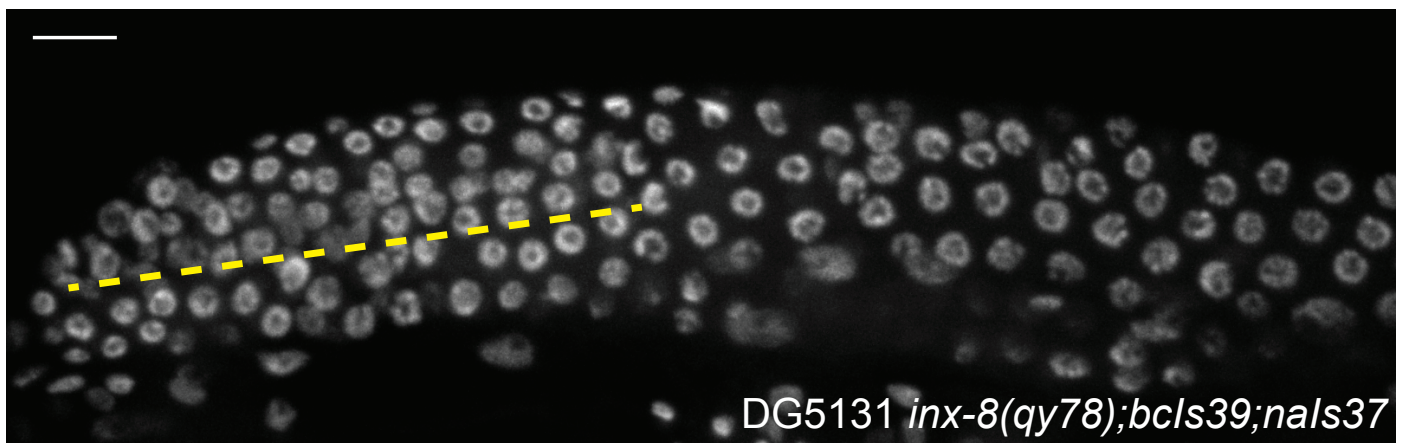

E

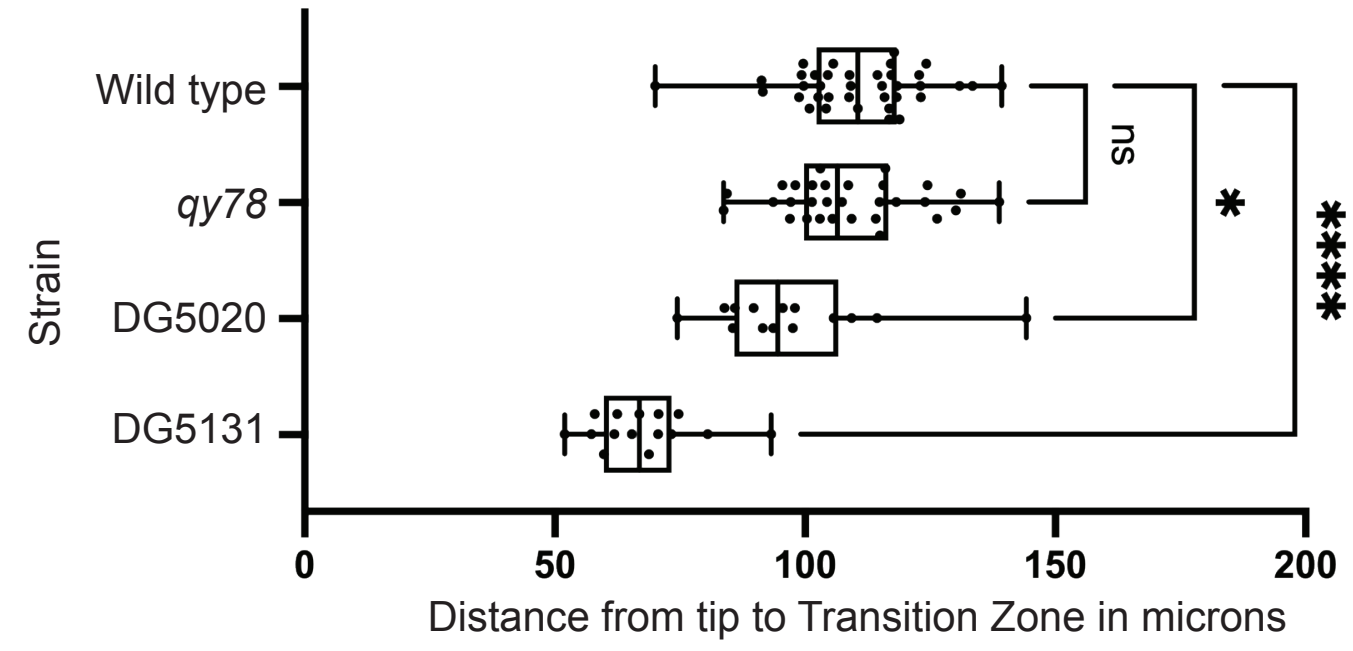


611 Figure 5. A synthetic interaction between lim-7p::ced-1::GFP and the tagged innexin qy78 shortens the proliferative zone. (A-D) DAPI staining of distal germ lines from wild type $\mathrm{N} 2(\mathrm{~N}=37)$, $(B)$ the strain with the tagged innexin qy78[mKate::inx-8], (N=30), (C) the DG5020 strain with lim7p::ced-1::gfp ( $\mathrm{N}=14)$, (D) and the DG5131 strain combining these sheath markers $(\mathrm{N}=15)$. Germ line proliferative zone length marked in each image with yellow dashed line. Representative images chosen had measurements within $10 \%$ of average measured for that strain. Boxplots showing length of proliferative zones for all strains. A one-way ANOVA to determine the effect of genotype on length of proliferative zone was significant $F_{3,92}=40.59$, $p<0.0001$. Tukey's multiple comparison test revealed that $q y 78$ did not differ from wild type (mean difference $1.91 \mu \mathrm{m}, 95 \% \mathrm{Cl}-6.758 \mu \mathrm{m}$ to $10.58 \mu \mathrm{m}$, $\mathrm{p}=.939$ ), DG5020 barely differed from wild type (mean difference of $12.97 \mu \mathrm{m}, 95 \% \mathrm{Cl} 1.1899 \mu \mathrm{m}$ to $24.04 \mu \mathrm{m}, \mathrm{p}=0.015$ ), and DG5131 dramatically differed from wild type (mean difference of $43.08,95 \%$ CI $32.28 \mu \mathrm{m}$ to $53.88 \mu \mathrm{m}, \mathrm{p}<0.0001$ ). DG5131 was also significantly different from both of its parent strains (DG5131 vs. qy78 mean difference of $41.14 \mu \mathrm{m}, 95 \% \mathrm{Cl} 30.01 \mu \mathrm{m}$ to $52.33 \mu \mathrm{m}, \mathrm{p}<0.0001$; DG5131 vs. DG5020 mean difference of $30.11 \mu \mathrm{m}, 95 \% \mathrm{Cl} 17.00 \mu \mathrm{m}$ to $43.22 \mu \mathrm{m}, \mathrm{p}<0.0001)$. All scale bars $10 \mu \mathrm{m}$. 
bioRxiv preprint doi: https://doi.org/10.1101/2021.11.08.467787; this version posted November 10, 2021. The copyright holder for this preprint Minimum Shich was not certified by peer review) is the author/funder. Allyights reserved. No reuse allowed without permission.

A

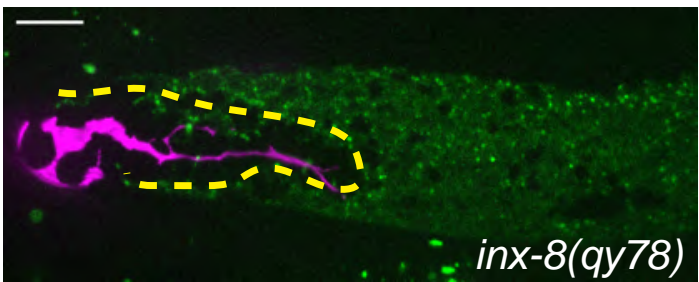

$\mathrm{B}$

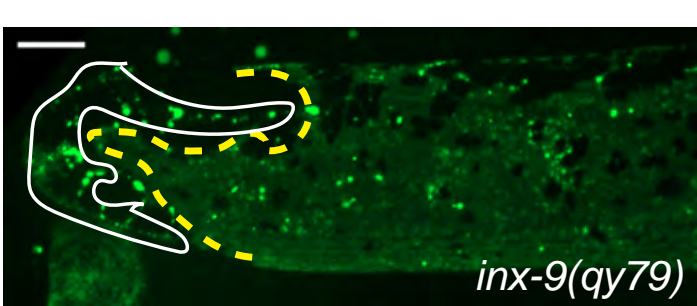

C

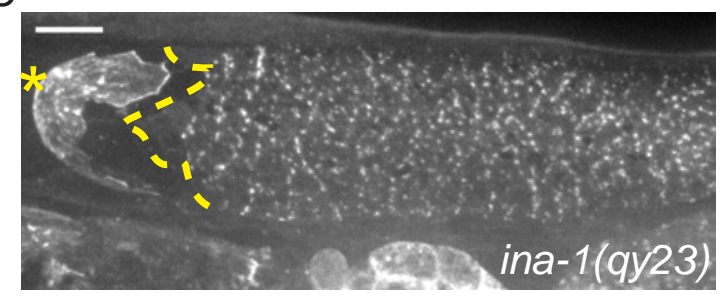

$\mathrm{D}$
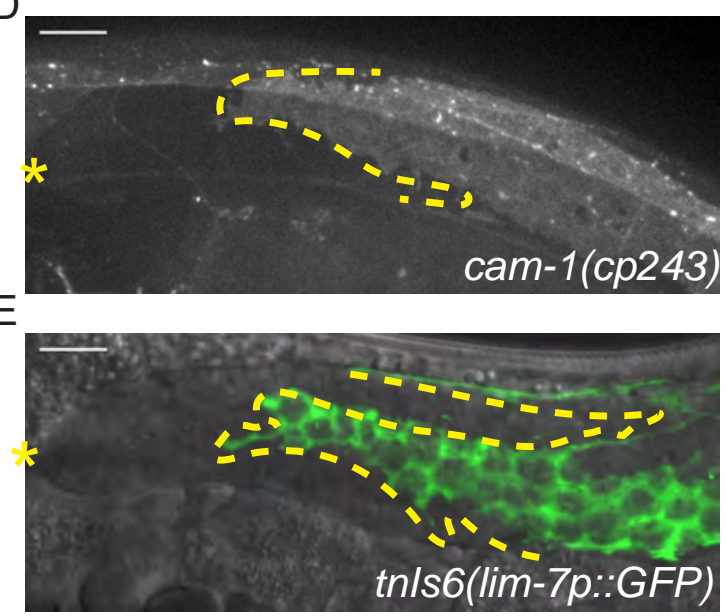

$\mathrm{F}$

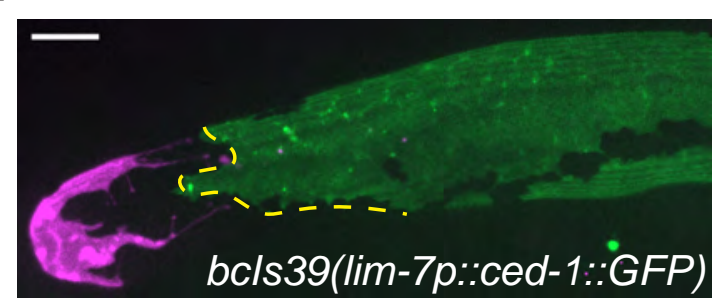

G

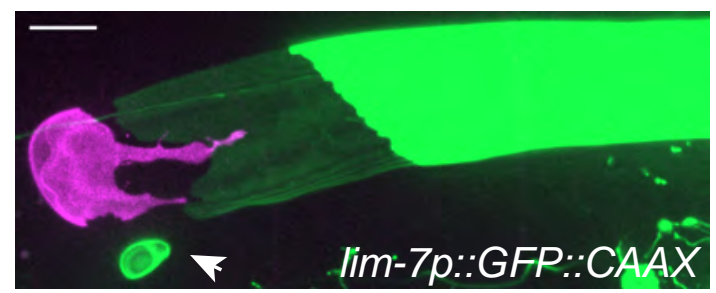

$A^{\prime}$
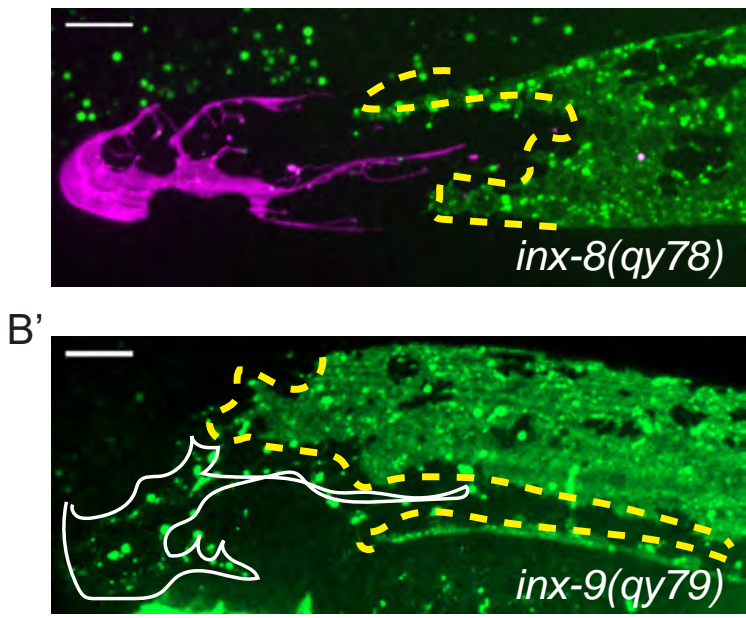

$C^{\prime}$

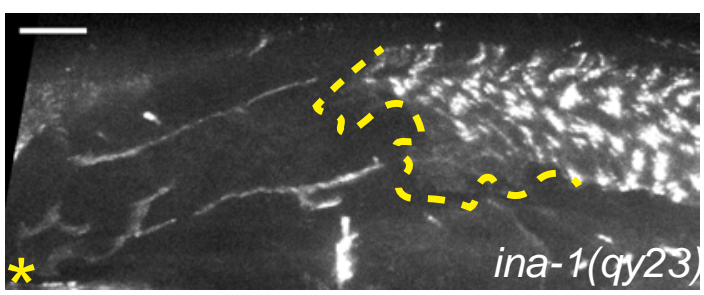

D'

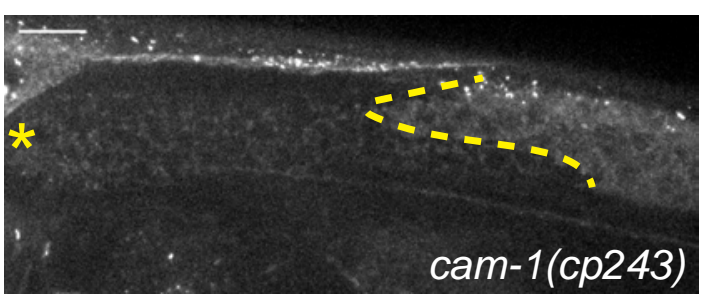

E

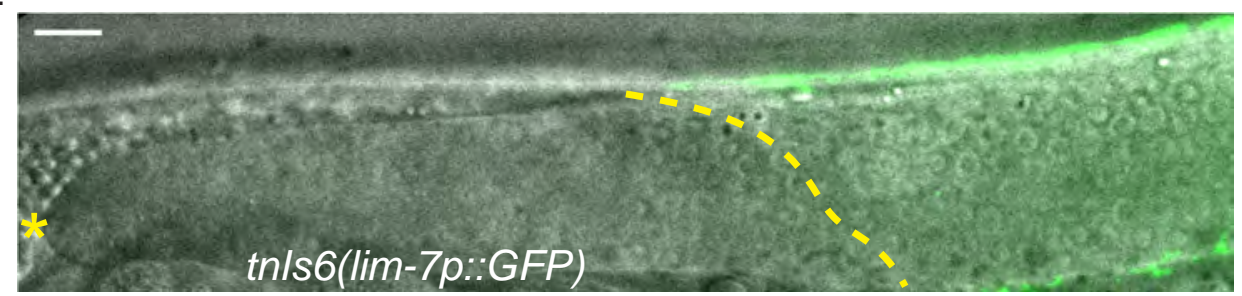

$F^{\prime}$

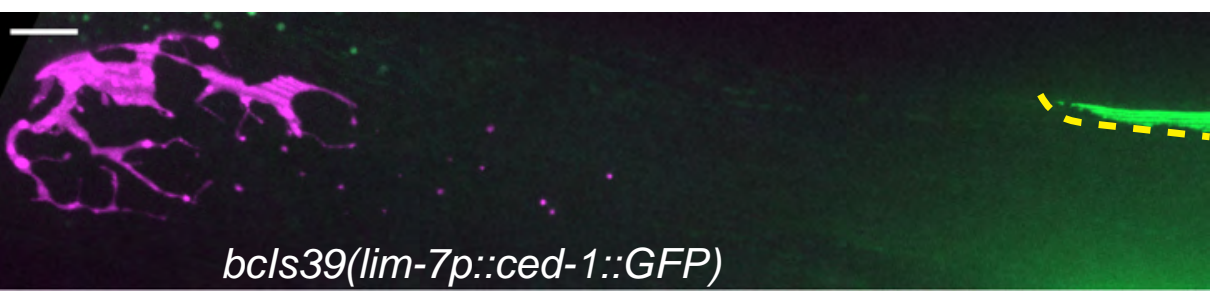

G

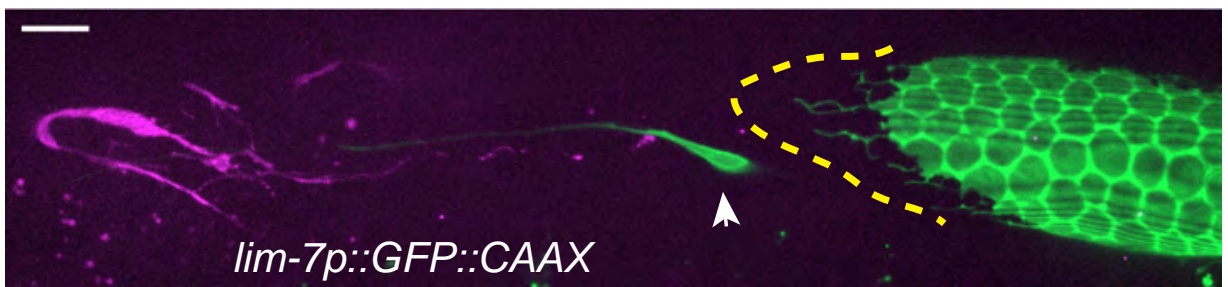

Figure 2

Supplement 1 
bioRxiv preprint doi: https://doi.org/10.1101/2021.11.08.467787; this version posted November 10, 2021. The copyright holder for this preprint (which was not certified by peer review) is the author/funder. All rights reserved. No reuse allowed without permission.

626 Figure 2 Supplement 1. Endogenously tagged fluorescent proteins in the Sh1 membrane are 627 less variable than overexpressed integrated transgenes. Minimum (left column) and maximum 628 (right column) measurements of the distance between distal Sh1 and the distal end of the gonad for (A, A') qy78[mKate::inx-8], (B, B') qy79[GFP::inx9], (C, C') qy23[ina-1::mNG], (D, D') cp243[cam$1:: m N G]\left(E, E^{\prime}\right)$ tnls6[lim-7::GFP], (F, F') bcls39[lim-7p::ced-1::GFP], (G, G') rlm/s5[lim7p::GFP::CAAX]. Arrowheads in G and G' mark non-sheath cells positive for lim-7p::GFP::CAAX expression that in plane with the gonad and are unavoidably included in Z-projections that capture the gonadal cell surface. Note especially in G how dim the Sh1 expression is at the distal extent, resembling what is sometimes seen for CED-1::GFP expression as reported by Figure 2 Figure Supplement 2B of (Tolkin et al., 2021). In some cases, the selected images are near-minimum or

636 near-maximum due to imaging artifacts like low illumination or sample movement in the true minimum or maximum images. All scale bars $10 \mu \mathrm{m}$. 
bioRxiv preprint doi: https://doi.org/10.1101/2021.11.08.467787; this version posted November 10, 2021. The copyright holder for this preprint (which was not certified by peer review) is the author/funder. All rights reserved. No reuse allowed without permission.

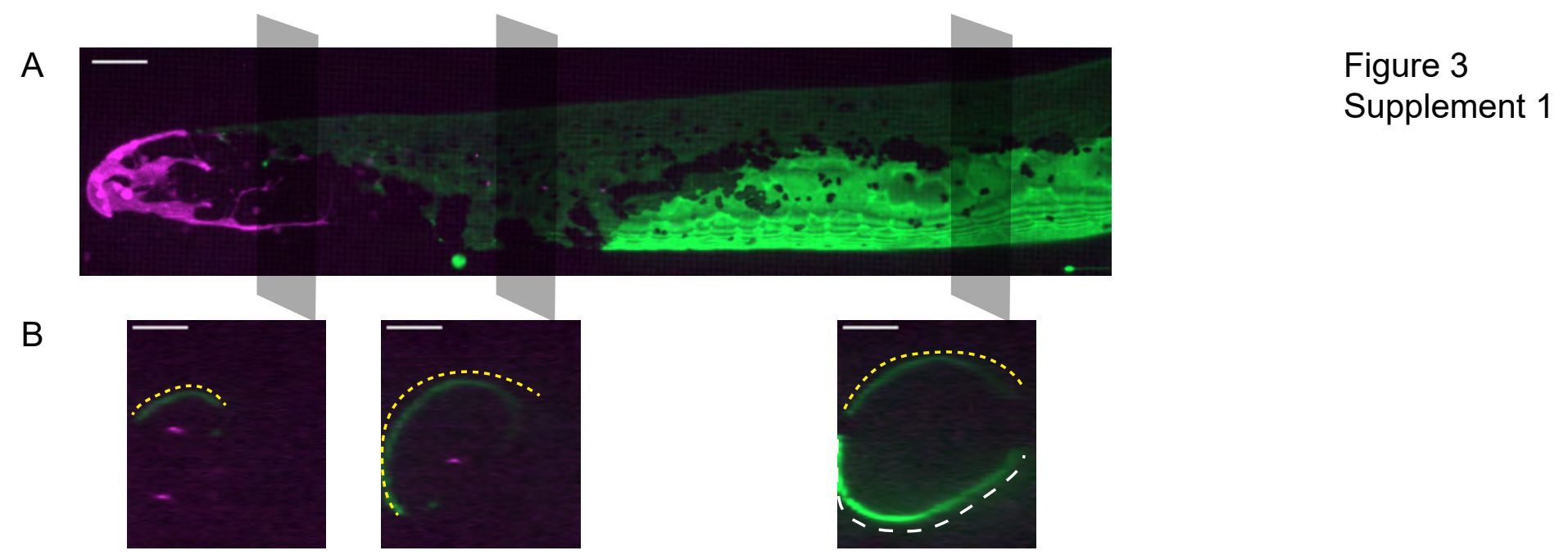

C

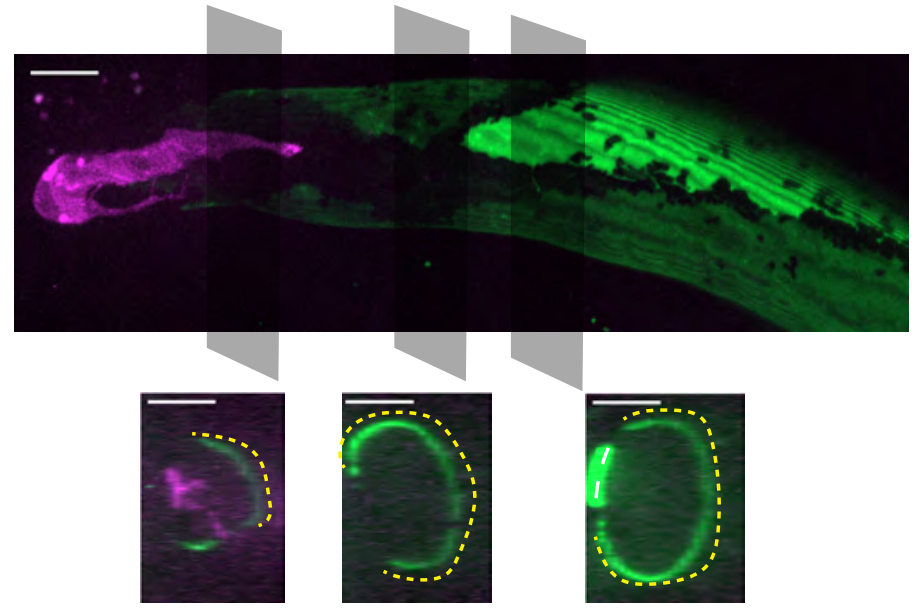

$\mathrm{E}$
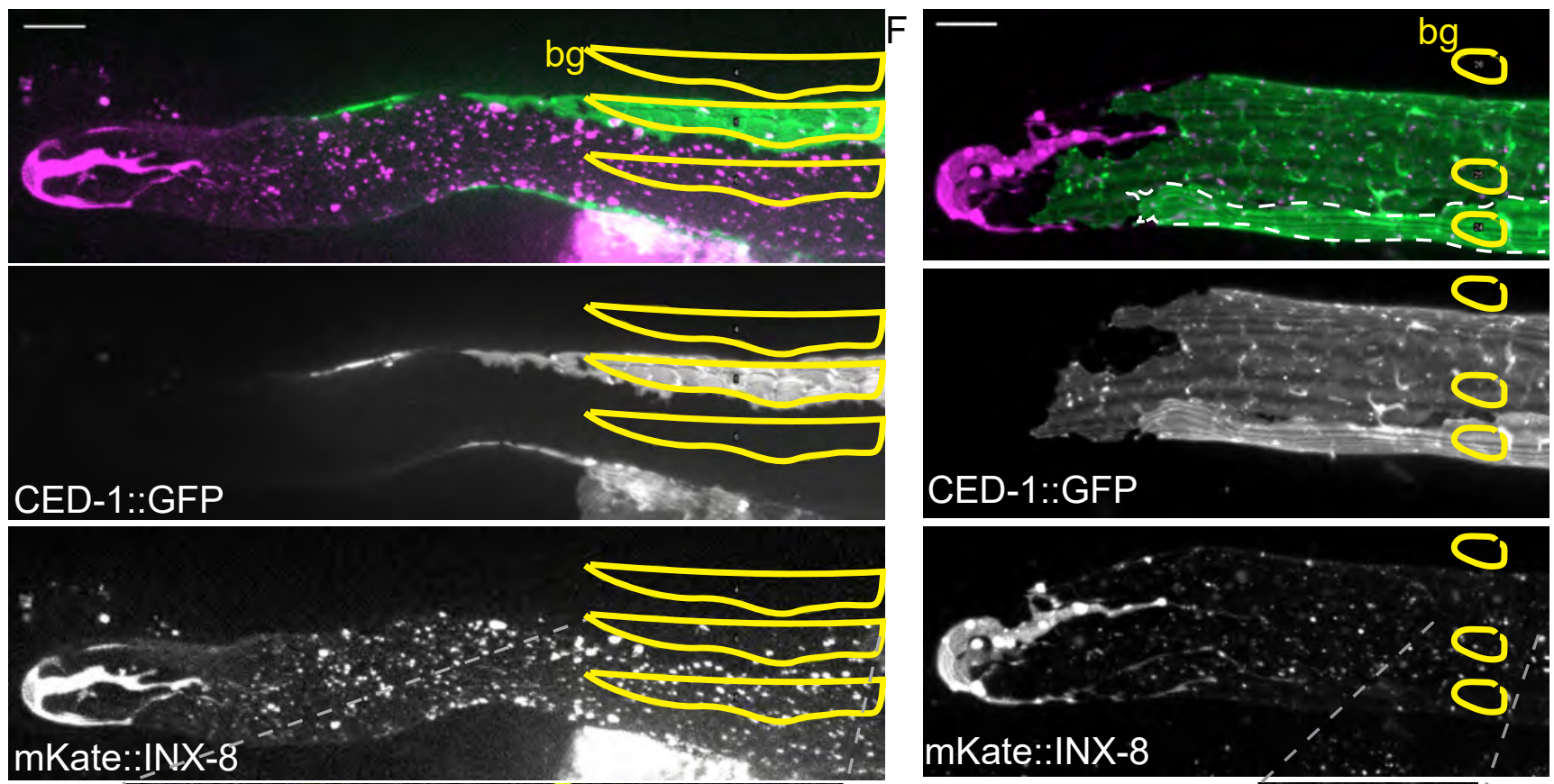

E
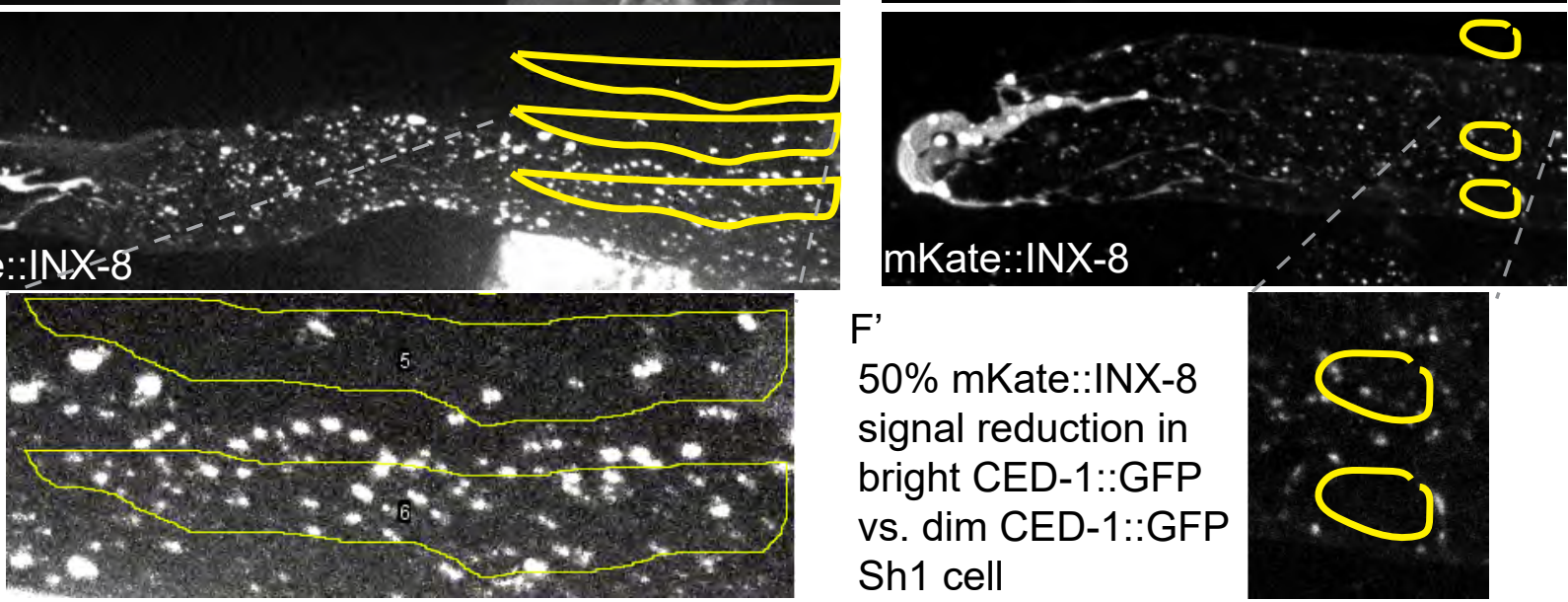

$F^{\prime}$

$50 \%$ mKate::INX-8 signal reduction in bright CED-1::GFP vs. $\operatorname{dim}$ CED-1::GFP Sh1 cell

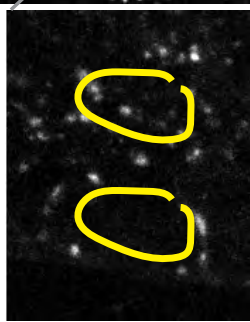


638 Figure 3 Supplement 1. The Sh1 cells of a pair can take two distinct configurations over the 639 distal germ line. (A) Example of a gonad from DG5020 lim-7p::ced-1::GFP animal with dramatically different CED-1::GFP signals revealing the shapes of the two Sh1 cells of the pair. Gray boxes show planes depicted in (B). (B) Three cross sections through gonad in (A) made by maximum projection through two $1 \mu \mathrm{m}$ re-slices (FIJI) at the positions shown by gray boxes in (A). Dashed yellow and white lines mark the two Sh1 cells. Depending on the proximodistal position of the gonad, one or the other Sh1 cell may surround more of the germ line. (C) Example of another gonad from DG5020. (D) Three cross sections through gonad in $(C)$ made by projecting through two $1 \mu \mathrm{m}$ re-slices at the positions shown by gray boxes in (C). (E,F) Gonads from strain DG5131 with merged images on top, CED-1::GFP channel in the middle, and mKate::INX-8 and distal tip marker channel on the bottom. Yellow outlines show regions of interest in which fluorescence intensity was measured. $\mathrm{bg}=$ background, subtracted from fluorescence intensity measured in each of the two Sh1 cells, which express CED-1::GFP at disparate levels. (E' and F') Insets from E and F. In both cases, mKate::INX-8 signal is half as strong in the Sh1 cells with more CED-1::GFP. Note also in E and F that mKate::INX8 and bright CED-1::GFP mark a different distal extent of Sh1. All scale bars $10 \mu \mathrm{m}$. 